\title{
Identifying Binding Constraints to Growth: Does Firm Size Matter?
}


Identifying Binding Constraints to Growth: Does Firm Size Matter?

Jose P. Mauricio Vargas 


\title{
IMF Working Paper
}

\author{
Research Department
}

\section{Identifying Binding Constraints to Growth: Does Firm Size Matter?}

\section{Prepared by Jose P. Mauricio Vargas ${ }^{1}$}

Authorized for distribution by Steve Phillips

January 2015

\section{This Working Paper should not be reported as representing the views of the IMF.} The views expressed in this Working Paper are those of the author(s) and do not necessarily represent those of the IMF or IMF policy. Working Papers describe research in progress by the author(s) and are published to elicit comments and to further debate.

\begin{abstract}
As emphasized by Hausmann, Rodrik and Velasco, the policy challenge of boosting growth requires prioritization and identifying what are the most binding constraints. This paper draws on firm-level data from the World Bank Enterprise Survey, which suggests that the obstacles for the functioning of firms is related to firm size. Recognizing the potential endogeneity and simultaneity between firms' constraints and firm size, we implement an Ordered-Probit model with a potential categorical endogenous regressor to estimate, for the case of Bolivia, the conditional probability of facing obstacles given the firm size category, while controlling for other factors. The results confirm the importance of allowing for the roles of firm size in identifying constraints and suggest priorities for policies to remove constraints to economic performance.
\end{abstract}

JEL Classification Numbers: D22, L25

Keywords: Firm Size, Firms' Constraints, IV-Oprobit, Bolivia

Author's E-Mail Address: MVargas@imf.org

\footnotetext{
${ }^{1}$ This document was initially prepared as a background paper for the Bolivian case study of the IADB Research Network project "Strengthening Mobility and Entrepreneurship: A Case for the Middle Class" and finished at the IMF. I thank Werner Hernani-Limarino, Steve Phillips, David Roodman, Jeffrey Wooldridge, and the participants in the Applied Research Workshops (Universidad Católica Boliviana) for their helpful comments, and Edgar Cáceres and Carola Tito for their able research assistance. All errors are my responsibility.
} 


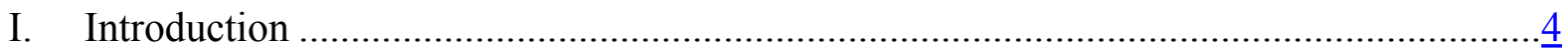

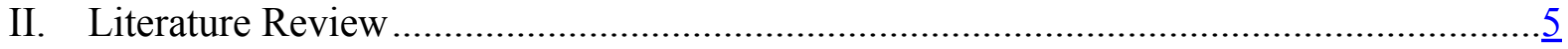

III. Some Stylized Facts for Bolivia ................................................................

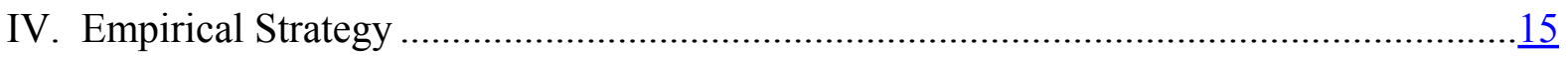

V. A Framework about Binding Constraints ............................................................... 15

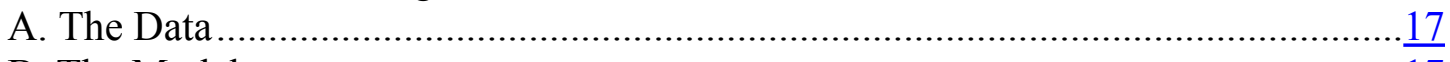

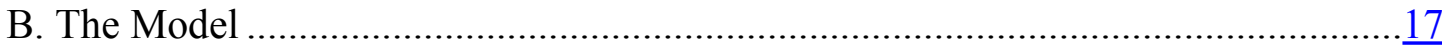

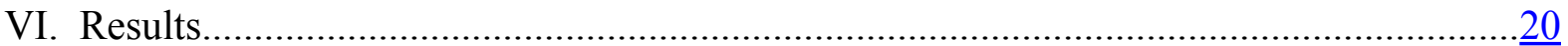

A. Firms Constraints: Does Firm Size Matter?.................................................... $\frac{21}{21}$

B. Binding Constraints...............................................................................

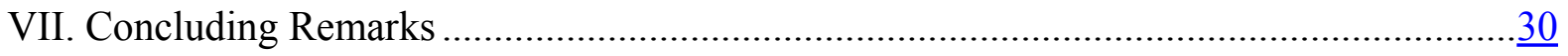

Appendixes

I. Proportion of Firms that Identify None, and Major or Severe Levels of Obstacles (By

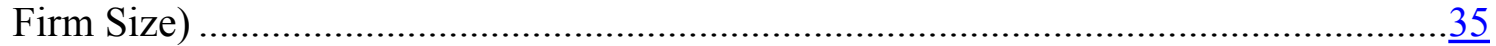

II. Model Selection (By Obstacle)............................................................................... $\frac{39}{47}$

III. Conditional Likelihood Minus Unconditional Likelihood of Facing Obstacles............... $\underline{47}$

Tables

1. Distribution of Firms That First Ranked this Obstacle as the Biggest Problem for the Establishment .......................................................................................................... 12

2. Correspondence of Factors Identified in the HRV Approach and the Set of Obstacles Available in the Enterprise Survey ................................................................................ 17

3. Summary of Model Selection Process …....................................................................

4. Model Results: Predicted Probability for a Representative Firm .................................. 22

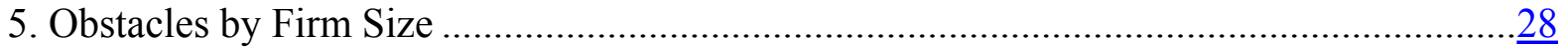

6. Ranking of Relative Worst Obstacles by Firm Size .....................................................29

Figures

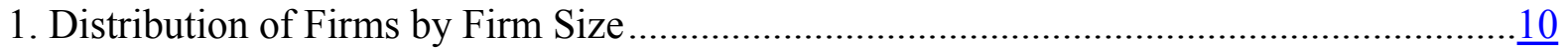

2. Business Environment Constraints for Firms in Selected Countries ( $\%$ of firms) ..............11

3. Proportion of Bolivian Firms that Identify the Issue as a Major or Very Severe Obstacle for the Establishment .................................................................................. 12

4. Proportion of Firms That First Ranked this Obstacle as the Biggest Problem for the

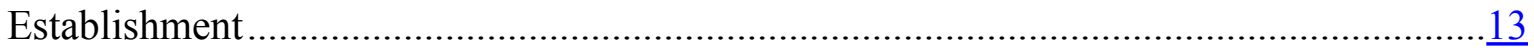

5. Level of Obstacle to the Functioning of the Establishment (Proportions)..........................13

6. Level of Obstacle to the Functioning of the Establishment (Proportions)..........................14

7. Growth Diagnostics (Hausmann, Rodrik \& Velasco, 2005)..........................................16 
8. Electricity: Marginal Effects of Firm Size ................................................................22

9. Telecommunications: Marginal Effects of Firm Size ...............................................23

10. Transportation: Marginal Effects of Firm Size ...............................................................24

11. Practices of Competitors in the Informal Sector: Marginal Effects of Firm Size..............24

12. Courts: Marginal Effects of Firm Size ................................................................ 25

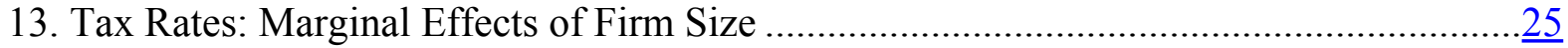

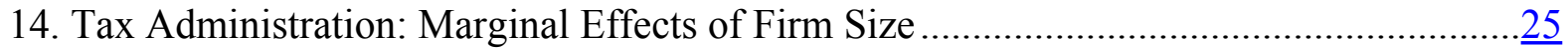

15. Business Licensing and Permits: Marginal Effects of Firm Size ................................. $\frac{26}{26}$

16. Access to Financing: Marginal Effects of Firm Size ................................................. $\frac{26}{28}$

17. Level of Obstacle to the Functioning of the Establishment ...........................................28

18. Level of Obstacle to the Functioning of the Establishment .........................................29 


\section{INTRODUCTION}

The analysis of causes and effects of firms' behavior is a fruitful field in economic research, including in identifying constraints to economic growth at the macro level. Since firms have a central role in the production process and therefore the determination of national output, it is important for public policy to be oriented to improving their performance. However, as emphasized by Hausmann, Rodrik and Velasco (HRV) (2005), developing economies face many constraints to growth, so the challenge for policy is to first identify which constraints are most binding in a given country. In that spirit, this paper draws on firm level data and applies an empirical model to identify what are the most relevant obstacles to firm performance in the case of Bolivia.

This paper brings new results on two branches of firm level empirical literature: i) differences between firms according to their size, and; ii) firms' binding constraints.

Our objective is twofold. First, we seek to verify whether Bolivian firms' constraint levels depend on firm size. Our review of theory and empirical research on firm size and firm constraints suggests that we should consider a potential endogeneity and simultaneity between both variables: firm size could be determined by a firm's constraints, while simultaneously firms' constraints could depend on firm size. Second, we identify and rank the most binding constraints for Bolivian entrepreneurs, distinguishing between small, medium, and large firms. To tackle both questions, we use the World Bank Enterprise Survey (ES) data to estimate the likelihood of different levels of obstacles, conditional on firm size.

The ES provides us with a sample of small, medium, and large formal firms in the three main cities of Bolivia. In our sample, each firm reports a level of obstacle (on an ordinal scale) associated with 16 potential constraints for the functioning of the firms. This set of constraints permits us to make a prioritized "diagnosis" of constraints that considers elements that are close to those proposed in HRV, which aims to identify the most binding constraints to growth, but in addition, we consider the role of firm size differences and implement an empirical model.

The structure of the ES data allows us to implement a novel estimation procedure: the Conditional (Recursive) Mixed-Process Model (CMP). We use this method to estimate one model for every potential obstacle that firms could face, considering constraint levels as functions of an ordinal regressor which is potentially endogenous (i.e. firm size). The CMP model allows us to find empirical evidence of the potential endogeneity described above, and to determine (in presence or absence of endogeneity) if size matters when explaining firms' constraints (see section 4).

Our results suggest that firm size, and other firm characteristics - such as ownership structure and industry type - do matter when analyzing firm's constraints, although some of the obstacles affect all kinds of firms broadly. These conclusions are valuable because they imply that we may consider particular public policy recommendations to address relevant 
constraints to firms with particular characteristics according to industry, sector, firm or geographical region. We compute an obstacle ranking which confirms that 'Corruption,' 'Crime, Theft and Disorder,' 'Informality' and 'Political Instability' seem to be common obstacles to all firms, while public services provision is a problem for medium and large firms (particularly 'Electricity' and 'Transportation' represent considerable obstacles for large firms and medium firms, and 'Telecommunications' for medium firms). Another result is that 'Access to Financing' is an important obstacle just for small firms.

The organization of the paper is as follows. In section II, we briefly describe the state of art on research about causes and effects of firm size and firms' constraints, and the background about the binding constraints literature. Section III shows some descriptive statistics of firms' performance in Bolivia. The fourth section details specifications of the proposed empirical models. Section V describes results, and section VI summarizes main findings.

\section{LITERATURE REVIEW}

This section discusses main results of the literature related to firm size and firm's constraints. We show that there is a good amount of evidence suggestive of an endogeneity between both concepts. After that, we briefly review the binding constraints literature, and show a framework able to support identification of binding firm constraints.

Analysis of firms' constraints and determinants of firm's size are fields that have been gaining in importance in recent years. One reason for this increasing interest might be the availability of panel data and cross section databases designed for characterizing firms' behavior. Their importance is evident considering that firms play an important role in the production process, and therefore their performance and success will determine output growth, employment, and success of the whole economy.

Firms' constraints could be considered as external factors ${ }^{2}$ which affect the decisions to become an entrepreneur and the firm success, but as we will explain below, their effects are not necessarily similar between distinct firm sizes, nor exogenous. In the same fashion, we could consider firm size as an endogenous choice of firms; furthermore, it could be an outcome caused by firm's constraints. Below, we briefly show the state of the literature in both areas: firms' constraints and firms' size, showing the links between them, and their relevance to determine entrepreneur behavior and firms' success.

\footnotetext{
${ }^{2}$ As we detail in Section IV, we consider a set of the following potential constraints: Infrastructure and Services (Electricity); Sales and Supplies (Transportation, Customs and Trade Regulations, Informality); Access to Land; Functioning of the Courts; Crime; Government Relations (Tax Rates, Tax Administration; Business Licensing, Macroeconomic Instability, Political Instability, Corruption); Financing; Labor (Labor Regulations, Inadequately Educated Workforce).
} 
Firms' constraints have been studied using different methods, in several regional and causal contexts. Some research papers identify firm's constraints as determinants of entrepreneurship or firm's performance, while some others study the determinants of these constraints. In the former group, Ardagna and Lusardi (2008) (using a micro dataset for 37 developed and developing countries) focuses on individual characteristics and countries' regulatory differences - and estimating probit and IV-probit models - find that personal entrepreneurship (status as an entrepreneur or not) is determined by individual characteristics, and that these last ones could be affected by regulations (constraints). HoltzEakin et al. (1994) find that inheritance (and inheritance size) affects the individual choice to become an entrepreneur. These findings would suggest effects of liquidity constraints on entrepreneurship. We can find a similar approach in Johansson (2000) which uses the Longitudinal Employment Statistics of Finland to estimate a probit model for the probability of making a transition from wage employment into self-employment. The paper supports the notion that an individual's level of wealth is a significant variable to explain this transition, thus suggesting the existence of liquidity constraints. On the other hand, Hurst \& Lusardi (2004) propose that in the United States the relationship between wealth and entry into entrepreneurship is essentially flat over the majority of the wealth distribution (below the 95 percentile), and there is no evidence that wealth matters more for businesses requiring higher initial capital. This shows, according to the authors, that liquidity constraints, while possibly important for some households, are not a major deterrent to small business formation in the United States, even though they could affect the optimal scale of the business.

However, the literature on firms' constraints is not only concerned with financial restrictions. Some studies, as Parker \& van Praag (2005) emphasize the role of human capital on entrepreneurial performance. They develop a theoretical model that includes not only capital constraints but investment of founders in human capital, taking into account potential endogeneity between these variables. Their empirical approach estimates an instrumental variable model using a cross section sample of Dutch entrepreneurs for the year 1995. Their main findings are: there is evidence that supports treating human and financial capital as endogenous variables; lower capital constraints lead to greater entrepreneurial performance; more years of education (human capital) is associated with lower capital constraints; and extra years of schooling enhance entrepreneurial performance.

Firms' constraints might be considered as determinants of firms' success as well. For instance, the literature on credit constraints (Greenwald and Stiglitz 1993; Schiantarelli 1995) suggests that they can cause a misallocation of resources in firm production and affect firm's profitability. In this framework, Rizov (2004), using balance sheets and profit and loss statements for Bulgaria (between 1997 and 1999), shows that firms with credit constraints have smaller profitability. In a similar approach, Halabí and Lussier (2010), in a study for the Chilean economy, estimate an ordered probit model that shows that firms that face larger constraints (structural constraints such as internet use or financial constraints such as working capital), have lower probability of success. 
However, analysis of firm constraints is not only related to interest in the effects of constraints as exogenous variables but also in the determinants of constraints as an endogenous variable. In the theoretical field, Clementi and Hopenhayn (2006) propose a dynamic model to derive endogenous borrowing constraints, which arise as part of the optimal design of a lending contract under asymmetric information. From the empirical side, Hobdari et al. (2009), using a panel data for Estonian companies between years 1993 to 2002, find that the probability of being financially constrained depends on the ownership status of the firms. In a similar fashion, Canton et al. (2010), use the Eurobarometer data covering 25 European countries to estimate a binary logistic model to get insights about the determinants of perceived financing constraints. Their findings show that financing constraints 3 depend on firm's age while ownership structures do not seem to have a systematical effect.

Regarding the second element of our interest - firm size - there are several papers treating it as either an endogenous and exogenous variable of firm's performance. A first insight on the subject is found in the survey collected by Bernardt \& Muller (2000) about determinants of firm size. They classify basic determinants of firm size within two groups: one at the firm level (i.e. economies of scale, transaction costs, agency costs), and the other at sector level (i.e. external economies of scale, network externalities); and additionally, they identify what they call trends and structural changes in firm size; this last item would consider the economic environment or external factors: that is, firm's constraints. Also, an extensive analysis is found Kumar et al. (1999), where, using a 15 European countries sample, the authors identify some industrial and country characteristics that affect firm size positively, namely: market size, capital intensive industries, high wage industries, industries that do a lot of $R \& D$, industries that require little external financing, efficient judicial systems, better financial markets.

Some other research focuses on firm's size as exogenous variable; for instance, Pagano and Schivardi (2003), using a dataset of eight European countries, found that larger firms' size fosters productivity growth because it allows firms to take advantage of all the increasing returns associated with $R \& D$. They support the view that firm size has a causal positive impact on growth.

In the above we have discussed firm's size and firm's constraints as if they were mutually independent variables; however, there is reason and some evidence to doubt such independence. Indeed, some of the empirical literature recognizes explicitly there is interdependence between firm's size and firm's constraints. Kumar and Francisco (2005), based on the Investment Climate Assessment Survey for Brazil, found that firm size strongly affects access to credit, and that this effect would be greater for longer-term loans. In

\footnotetext{
${ }^{3}$ The dependent variable takes value 1 if the answer to:"Would you say that today, access to loans granted by banks is very easy, fairly easy, fairly difficult or very difficult?" is either "very difficult" or "fairly difficult" and takes value 0 if the answer is either "very easy" or "fairly easy".
} 
addition, they suggest that public financial institutions are more likely to lend to large firms. In their study, they estimate a probit model and a two-step maximum likelihood probit with sample selection, both to measure the probability of having a loan.

The work of Kounouwewa and Chao (2011) supports the results of Kumar and Francisco (2005). Their article, based in information from the World Business Environment Survey (WBES) for 16 African countries, finds that firms size and ownership structure are useful to explain financing constraints. Moreover, they show that institutional development is the most important country characteristic to explain cross-country variation in firm's financing obstacles. Their methodological and empirical approach is based on the estimation of an ordered probit regression for the response to the question: How problematic is financing for the operation and growth of your business? The authors include the size of the firm in the set of control variables. In a similar fashion, Beck et al. (2005), using a database covering 54 countries from WBES, find that financial, legal, and corruption constraints depend on firm size, and smallest firms are most constrained.

Furthermore, some papers suggest a reverse causality in which firm's constraints affect firm's size. For instance, Angelini and Generale (2005), from a survey dataset of Italian firms and the WBES, found that financial constraints may affect firm size distribution; this effect would be stronger in developing countries. Fagiolo and Luzzi (2006), for Italy too, look for an answer to an almost identical question: do liquidity constraints matter in explaining firm size and growth? Some of their findings, based on panel data for the manufacturing sector, are that liquidity constraints have a negative effect on growth, and that small firms grow more, even after controlling for liquidity constraints.

Finally, we note two theoretical approaches which contribute to explaining potential effects of financial constraints on firm's size: Cooley and Quadrini (2001), and Cabral and Mata (2003) suggest that financing constraints could explain the distribution of firm size and its evolution over the time. The former, using a model with firm heterogeneity in which longlived firms solve a dynamic intertemporal optimization problem, concludes that financial factors are crucial in differentiating the production and investment decisions of firms of different size and this generates dynamics of entry, exit and growth; in turn, the latter constructs a two-period model of a competitive industry where firms face financial constraints in the first period while in the second period firms are no longer subject to financing constraints. The authors calibrate this model for Portuguese manufacturing firms, and show that it does a good job explaining the evolution of the firm size distribution.

So far, we have reviewed evidence that supports the links between firm's size and firm's constraints with performance and enterprise decisions. From this perspective, it is clear that we should consider a potential endogeneity between firm's constraints and firm's size when trying to evaluate if firm's perceived constraints depend on firms' size. Our contribution aims to consider this issue. 
As stated above, our second objective is to get evidence about the most binding constraints for Bolivian firms. To tackle this question we rely on a theoretical framework developed by HRV (2005). In fact, they propose that low growth is primarily due to low levels of private investment and entrepreneurship. Then, based on a simple theoretical model, they divide the factors affecting growth into two categories: High Cost of Financing, and Low Return to Domestic Investment. In turn, these two categories can be associated with various sub-factors that could be driving low growth (see subsection 4.1 for more details). One of the main suggestions of that paper is that policymakers should be concerned about identifying the most binding constraints because governments face administrative and political limitations, so their strategies must be carefully prioritized.

In an applied fashion, and following closely the Haussman et al. approach, Dinh et al. (2010) identify the most binding constraints on firms operations in developing countries. They use the World Bank Enterprise Survey between 2006 and 2010 and find that access to finance is among the most binding constraints, especially for small firms, which could play a significant part in explaining why small firms do not grow into medium and large firms. They estimate three econometric models for explaining the employment growth of firms. Under their definition, the most binding constraint would be that which explains most strongly the growth of firms (with a negative sign).

A similar exercise is found in Aterido et al. (2009). Using the World Bank Enterprise Surveys for 90 countries between 2000 and 2006, the authors seek to identify which firms' characteristics are more significant to explain investment climate conditions focusing on 4 areas: access to finance, business regulations, corruption, and infrastructure; they run multiple regression models to estimate the impact of investment climate conditions on firm's employment growth. Their main objective is to assess whether there are heterogeneous effects of unlocking business environment constraints. In a similar fashion, Bari et al. (2005) identify growth binding constraints for Pakistan based on results of the Pakistan Economic Survey 2001-02. They were concerned also with firm size differences, especially in the key role of small and medium enterprises. Likewise, using panel data between 2006-10, Dinh et al. (2010) constructed three specifications to explain firm growth from which they define the most binding constraint to the one whose variable coefficient '...is statistically significant, has a large coefficient in all estimations (models), and has the right sign...'. Our approach to identifying the most binding constraint is placed somewhere between the strategies mentioned above, and as we will explain broadly in section 4, we try to verify if firm's characteristics (especially firm size) could affect the likelihood of facing more obstacles to firms' performance.

Finally, we note that the Growth Diagnostic approach of Hausmann et al. (2005) was previously implemented for the Bolivian economy, in Calvo (2006): that study suggests that a high risk in the appropriation of returns due to macro and micro risks may be the most binding constraint. This reflects on uncertainty of fiscal and financial sectors, weak property 
rights, and high corruption levels. Also, she rejects that infrastructure and education might be binding constraints at that time. To some extent, our paper is devoted to the same goal, ${ }^{4}$ but relies more intensively on survey data and exploits it by using econometric methods.

Under this framework, the next section shows new evidence about Bolivian firms and their constraints.

\section{SOME STYLIZED FACTS FOR BOLIVIA}

This section analyzes main characteristics of firm size, and firms' constraints, in Bolivia. The questionnaire of the World Bank Enterprise Survey 2010 for Bolivia includes 16 potential issues that may represent obstacles for the functioning of firms. ${ }^{5}$ It also classifies firms in three categories: small (between 5 and 19 workers), ii) medium (between 20 and 99 workers), and iii) large (more than 100 workers). Table 1 compares Bolivian firms' structureaccording to their size - with respect to some other countries in the Latin American region. Patterns between countries are somewhat divergent; however they present a clear pyramidal structure for some countries: Bolivia, Argentina, Peru, and Uruguay, all of them showing a large proportion of small firms in the pyramid's base and a small share of large firms in the pyramid's peak. On the other hand, Chile and Mexico show a firm size structure that depends more heavily on medium and large firms.

Figure 1. Distribution of Firms by Firm Size

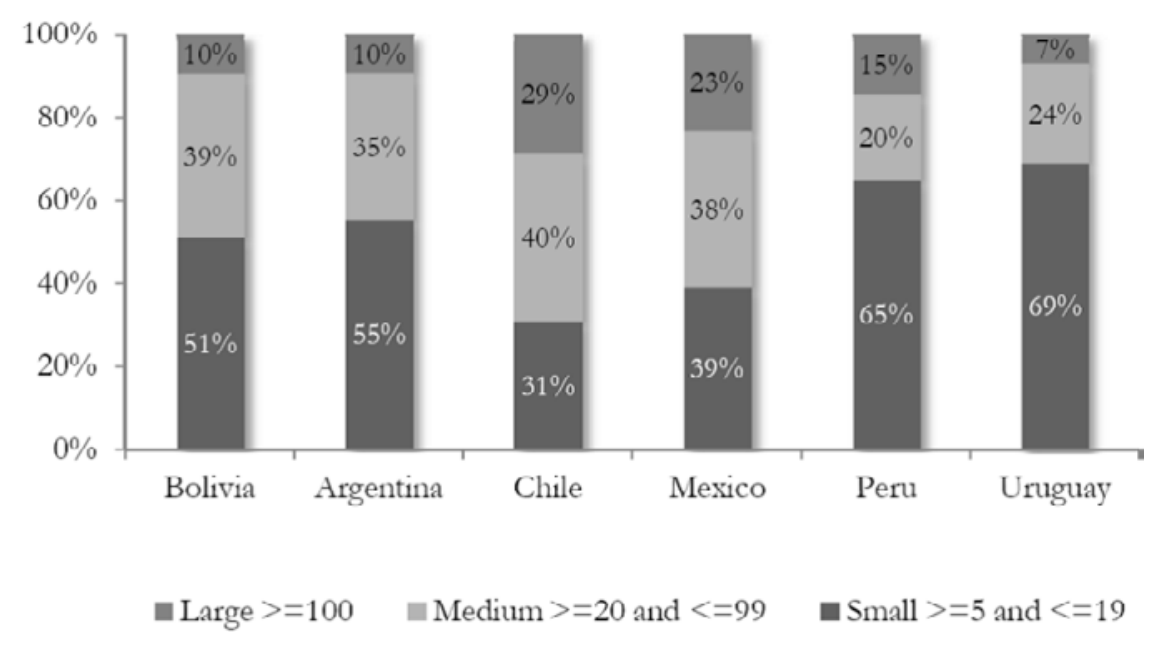

\footnotetext{
${ }^{4}$ Strictly speaking, we rank the obstacles that more strongly affect firms' performance rather than firms' growth. While performance and growth might be closely related, an extrapolation of our results should be interpreted with caution.

${ }^{5}$ Firms are asked to issue their perception on each of these 16 potential obstacles for their functioning. The set of answers is constrained to the next five options: No Obstacle, Minor Obstacle, Moderate Obstacle, Major Obstacle, and Very Severe Obstacle.
} 
Regarding firms' constraints, Figure 2 compares the share of firms identifying any of the 16 obstacles as being the worst obstacle for its functioning. It reveals that, among the six regional countries included in the analysis, Bolivia has the worst perception about 'Practices of Competitors in the Informal Sector' and 'Political Instability.' If we take into account only the three worst obstacles for each country, we can find some common issues: 'Competitors Practices in the Informal Sector' represents a problem in 4 countries, Mexico (16\%), Peru (29\%), Uruguay (23\%), and Bolivia (37\%); 'Inadequately Educated Workforce' is perceived as a problem in Chile (22\%), Peru (13\%), Uruguay (12\%), and Bolivia (12\%); 'Tax Rates' obstacle is considered important in Uruguay (24\%), Argentina (20\%), and Mexico (14\%), and finally; 'Access to Financing' obstacle represents a constraint for firms in Argentina (15\%), Chile (12\%), and Mexico (12\%).

Figure 2. Business Environment Constraints for Firms in Selected Countries ( $\%$ of firms)

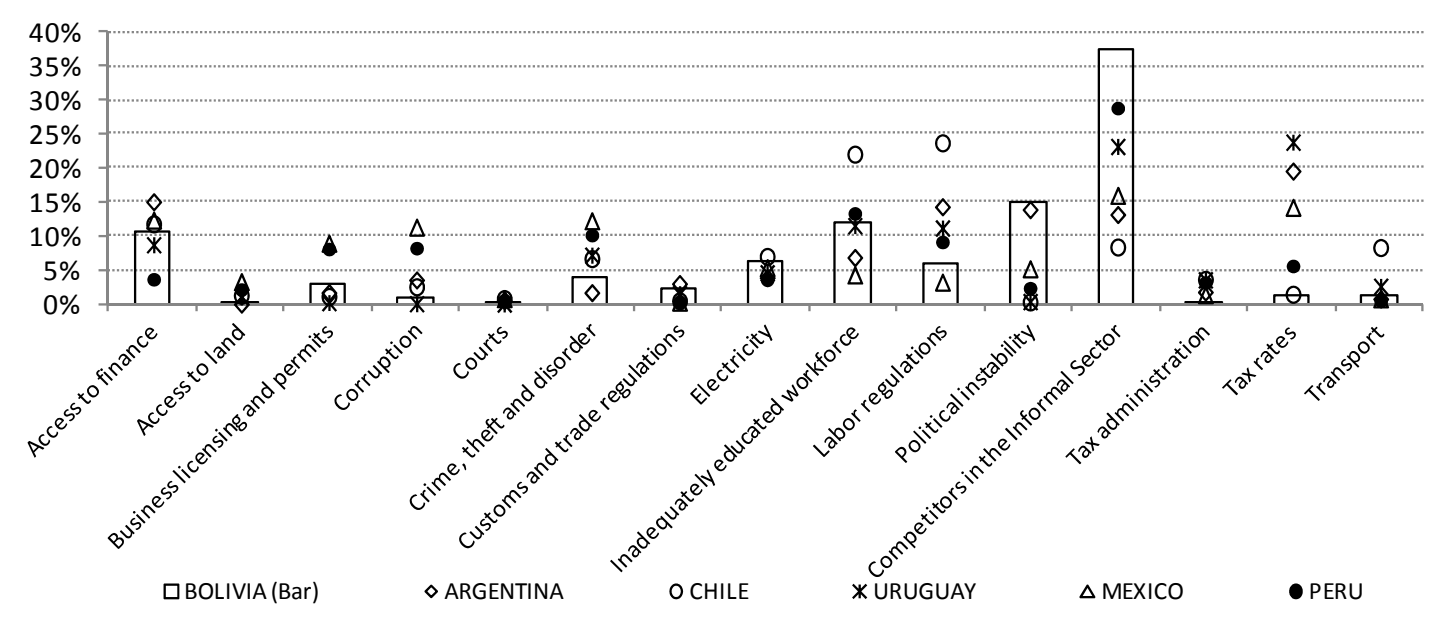

Figure 3 shows the share of all Bolivian firms that considered each obstacle as a major or very severe issue. From this chart, it is easy to identify the most worrying elements: Corruption, Practices of Competitors in the Informal Sector, Political Instability, and Crime Theft and Disorder, in that order. On the other hand, Tax Administration, Tax Rates, Business Licensing and Permits, and Access to Land seem to represent lesser problems for the functioning of firms.

Our objective, beyond just identifying main constraints that typical firms face, is to determine whether each particular obstacle affects firms with different intensity according to firm size. Our database of Bolivian firms contains a sample of 126 small firms, 149 medium firms and 87 large firms. One might suppose that behavior between groups would not be homogeneous, and indeed, the results in Table 1 suggest that the worst constraints are not common to all sizes of firms. In fact, only 2 of the top 5 ranked worst obstacles are common between different firm sizes: Practices of Competitors in the Informal Sector, and Inadequately Educated Workforce. 
Figure 3. Proportion of Bolivian Firms that Identify the Issue as a Major or Very Severe Obstacle for the Establishment

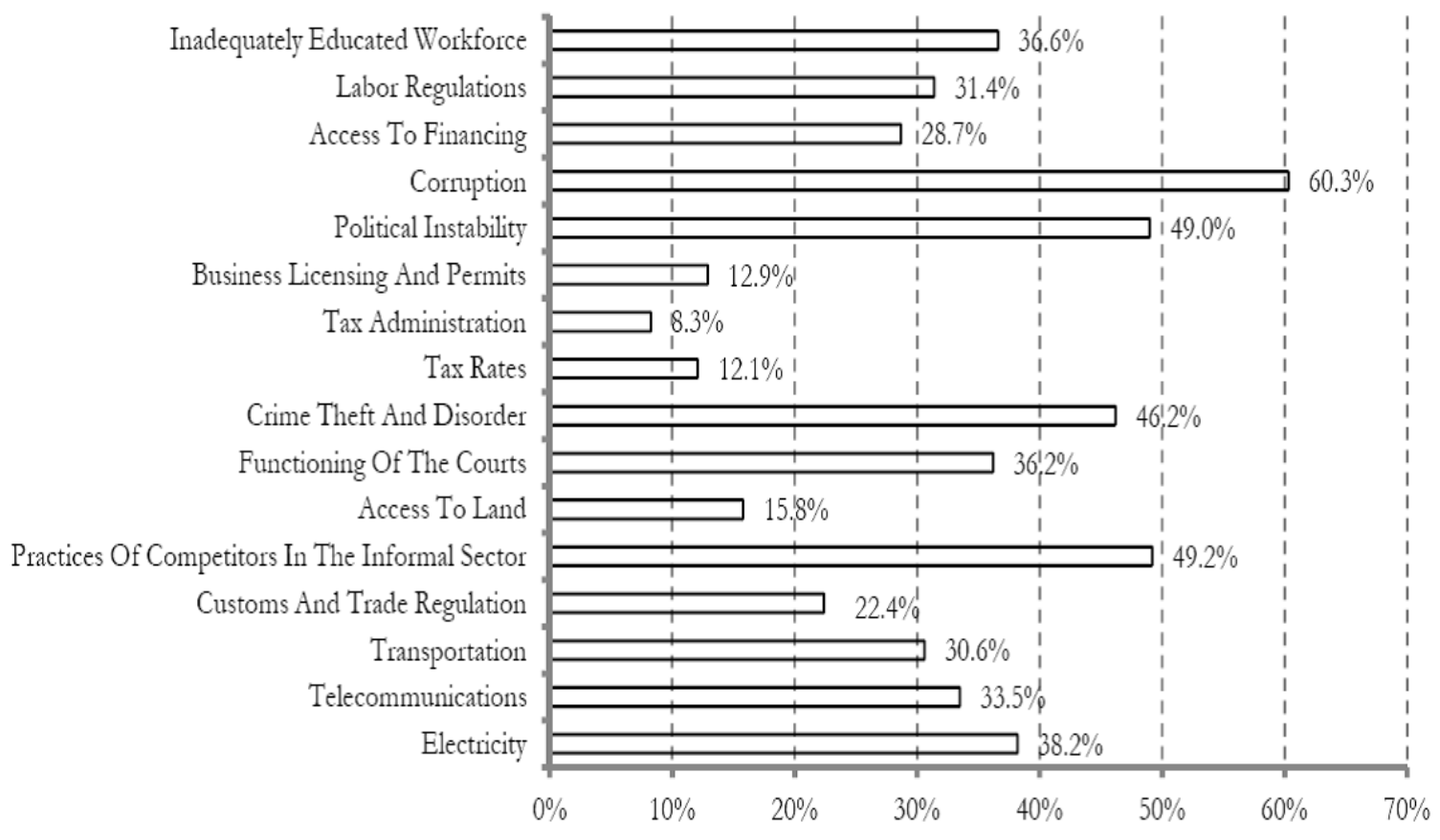

Table 1. Proportion of Firms That First Ranked this Obstacle as the Biggest Problem for the Establishment

\begin{tabular}{lr}
\hline \multicolumn{2}{c}{ Very Small and Small Firms } \\
\hline \hline Practices Of Competitors In The Informal Sector & $41.7 \%$ \\
\hline Inadequately Educated Workforce & $13.2 \%$ \\
\hline Access To Financing & $12.3 \%$ \\
\hline Labor Regulations & $7.1 \%$ \\
\hline Electricity & $5.8 \%$ \\
\hline \multicolumn{1}{c}{ Medium Firms } \\
\hline \hline Political Instability & $27.0 \%$ \\
\hline Practices Of Competitors In The Informal Sector & $25.8 \%$ \\
\hline Inadequately Educated Workforce & $14.0 \%$ \\
\hline Access To Financing & $11.3 \%$ \\
\hline Electricity & $8.9 \%$ \\
\hline \hline Practices Of Competitors In The Informal Sector & \\
\hline Political Instability & $59.1 \%$ \\
\hline Customs And Trade Regulation & $15.6 \%$ \\
\hline Labor Regulations & $8.6 \%$ \\
\hline Inadequately Educated Workforce & $5.4 \%$ \\
\hline
\end{tabular}


Figure 4. Proportion of Firms That First Ranked this Obstacle as the Biggest Problem for the Establishment

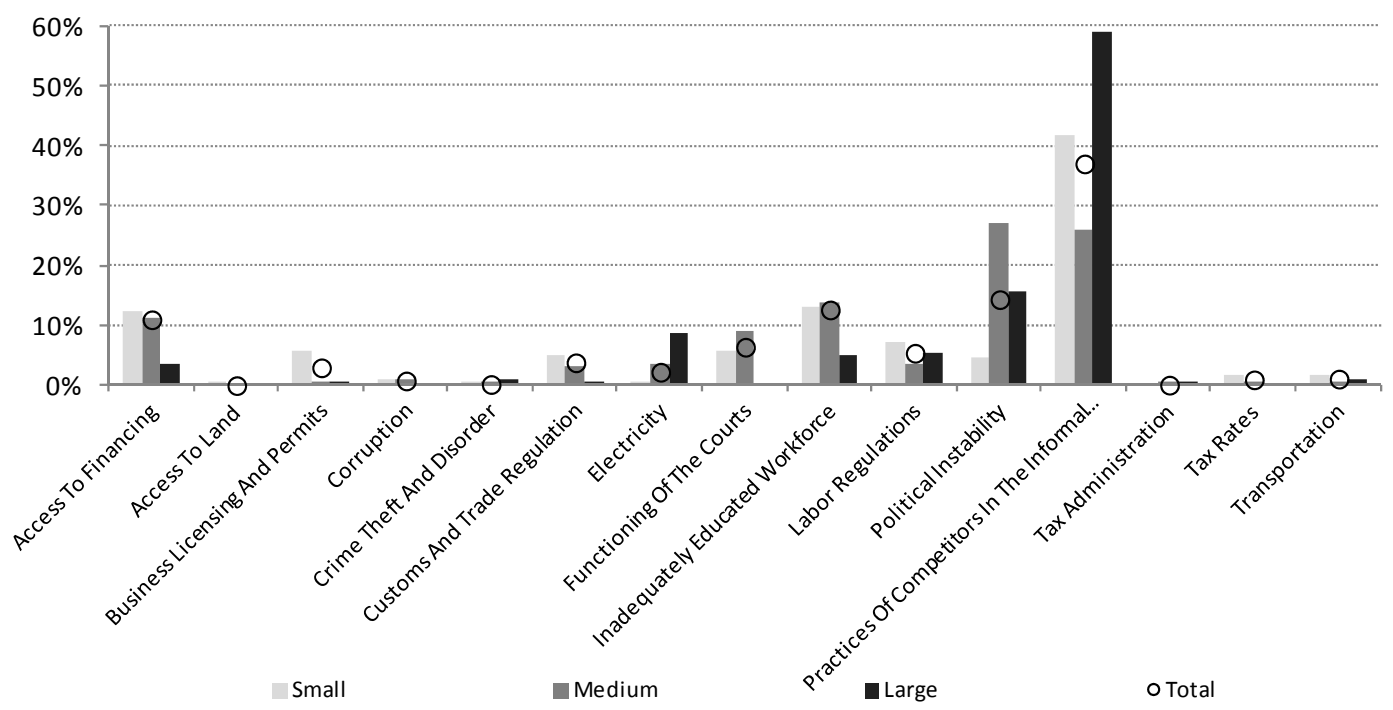

To get a second look at the firm size - firm's constraints relationship, we calculated the proportion of small, medium, and large firms that answered that a given obstacle represents: i) no obstacle, ii) minor obstacle, iii) moderate obstacle, iv) major obstacle, and v) a very severe obstacle. The following figures show each obstacle distribution. ${ }^{6}$

Figure 5. Level of Obstacle to the Functioning of the Establishment (Proportions)
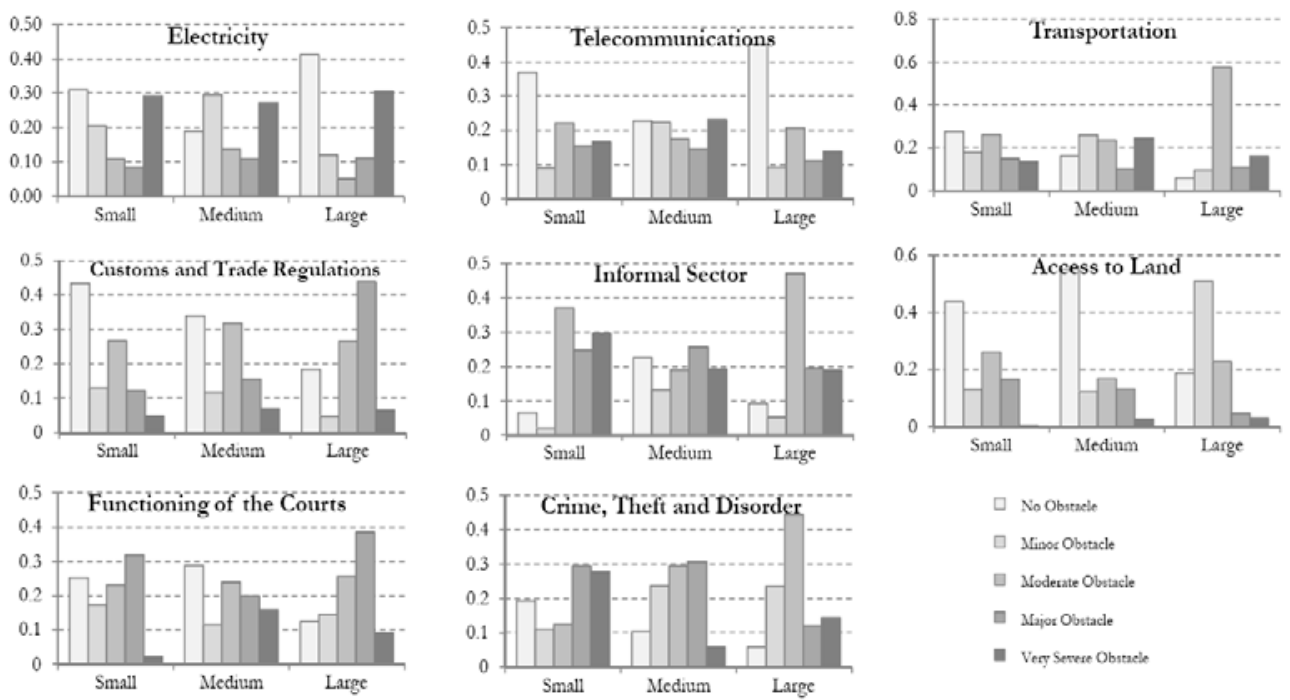

${ }^{6}$ Data including confidence intervals is reported in Appendix A. 
Figure 5, considering 8 of the 16 constraints covered by the survey, shows that firm size dimension is relevant in the analysis. For instance, small firms are likely to perceive that 'Crime, Theft and Disorder' represents a serious problem: 57 percent of small firms state that it represents a major or severe obstacle. On the other hand, only 2 percent of large firms believe it represents a major or severe obstacle. ${ }^{7}$ Another significant difference is observed for 'Customs and Trade Regulation' obstacle, 17 percent of small firms answered that it represents a major or very severe obstacle, while 50 percent of large firms responded the same.

Figure 6. Level of Obstacle to the Functioning of the Establishment (Proportions)
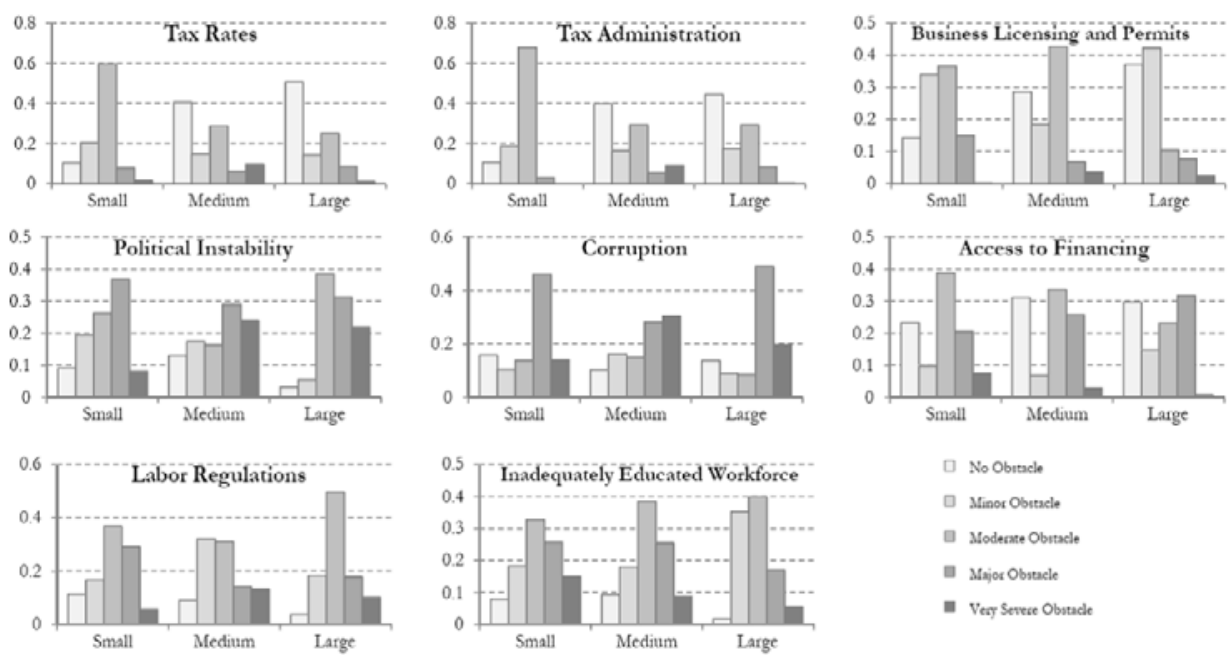

Figure 6 shows analogous charts for the complementary set of constraints covered by the survey. For example, the second graph in first column shows that 45 percent of small firms, 53 percent of medium firms, and 53 percent of large firms identify 'Political Instability' as a Major or Very Severe Obstacle. Thus, Figure 5 suggests that Political Instability might be a major obstacle for all kinds of firms. On the other hand, 'Tax Rates' obstacle seems to be perceived differently between firm size categories, indeed, a 50 percent of large firms identify that 'Tax Rates' represent no obstacle to their functioning, while just 10 percent small firms agree with that.

For some obstacles, a simple visual examination does not suggest much difference among firms. For example, 'Access to Financing' seems to represent no obstacle for about 23-30 percent of firms (no matter their size), while it represents a major or severe obstacle for almost one third of the firms (no matter their size either). While the above insights based on visual examination are suggestive, in Section IV we will apply a formal approach with more appropriate instruments of analysis.

\footnotetext{
${ }^{7}$ In fact, we may confirm this descriptive analysis through Wald Tests over the proportions to support statistical differences.
} 
Summarizing this section, Bolivian firms overall differ from those of other regional countries because they seem to face more trouble concerning 'Competitors in the Informal Sector' and 'Political Instability.' In addition, when asked to identify the severity of constraint for each potential obstacle, 60 percent of Bolivian firms agree that 'Corruption' is a major or very severe issue. We should expect that these three major constraints could be an important part of our results about binding constraints. On the other hand, the descriptive analysis suggests that in contrast to the other countries, Bolivian firms do not consider tax rates as a major constraint.

For our purposes, an essential finding is that firms, classified by their size, seem to differ in the obstacles they face. For example, results suggest that large firms face higher probabilities for considering 'Tax Rates' as no obstacle, and that small firms consider 'Customs and Trade Regulations' less harmful than large firms. However, the bivariate analysis of this section excludes interactions with some other relevant variables, such as the productive sector the firm belongs to, just to mention one. The empirical strategy that we describe below is intended to overcome this concern, and give a more accurate answer to the firms' size dependence, and - at the same time - provide a more precise metric to identify most binding constraints.

\section{EMPIRICAL STRATEGY}

Our assessment to find empirical evidence about: i) firm size as a key indicator of firm's constraints, and ii) most binding constraints, requires a comprehensive database characterizing firms in Bolivia. For this we take advantage of the World Bank Enterprise Survey project which includes firms' perception on a set of potential obstacles in addition to other firms' characteristics. Below, and considering Enterprise Survey data, we develop a structure to frame the results of section 5 .

\section{A Framework about Binding Constraints}

As mentioned, we will follow the general HRV theoretical framework for explaining low levels of private investment and entrepreneurship. Basically, HRV note that growth is driven by investment, in turn, investment depends on other variables related with economic environment. Figure 7 shows this scheme in a decision tree for a diagnosis of constraints to growth. The HRV growth diagnostics approach argues that Low Returns or High Cost of Finance can explain low levels of economic activity. Then, these two potential variables comprise, in turn, an extensive set of more specific determinants. For example, Low Returns to Economic Activity could be the result of Low Appropriability of these returns, which in turn are explained by Government Failures, specifically High Taxes. Table 2 shows a correspondence between HRV growth diagnostics and our set of potential binding constraints. This correspondence is intended to project the set of ES potential obstacles onto the HRV framework, so we can identify whether Low Social Returns, Low Appropriability or High Cost of Finance are more relevant for each kind of firms according to their size. 
While recognizing that most or even all of these constraints could be relevant, the purpose of the HRV approach is to identify the most binding constraints, considering them as the ones that 'are likely to provide the biggest bang for the reform buck.'

The HRV approach identifies a set of growth determinants, but it does not restrict the analysis to any particular methodology. In fact, HRV applied a growth diagnostic exercise to Brazil, El Salvador, and Costa Rica using stylized facts of each country; in this regard, they do not propose a particular empirical method or quantitative tool, ${ }^{8}$ thus we consider that our methods might be complementary to their analysis.

Figure 7. Growth Diagnostics (Hausmann, Rodrik \& Velasco, 2005)

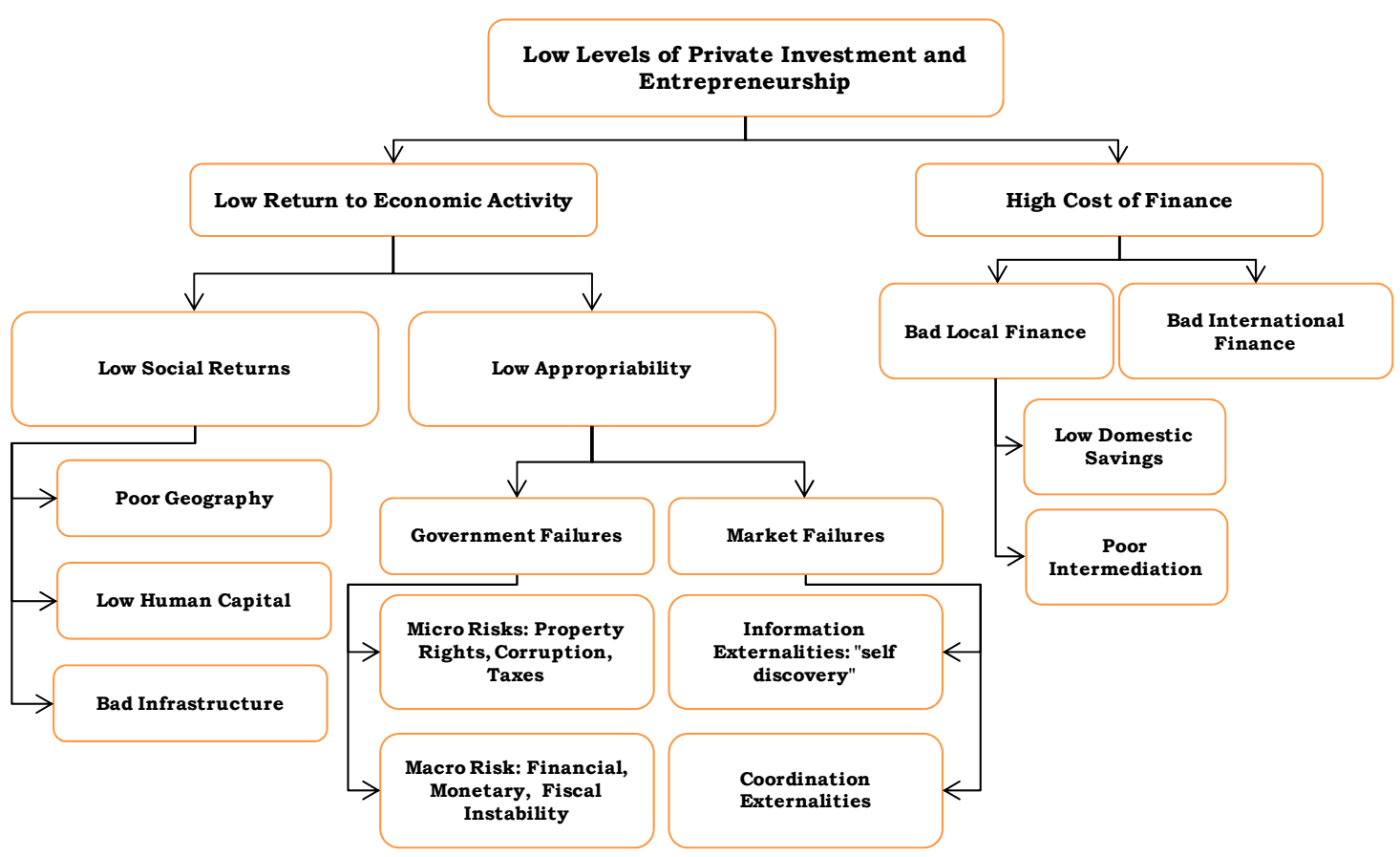

For our purposes, we will say that the most binding constraint to firms are those obstacles which represent the highest likelihood of being perceived as a major or very severe obstacles, conditional on firm size and a set of additional firm's characteristics.

\footnotetext{
${ }^{8}$ An extensive guide for applying HRV 'Growth Diagnostics' can be found in Hausmann et al. (2008).
} 
Table 2. Correspondence of Factors Identified in the HRV Approach and the Set of Obstacles Available in the Enterprise Survey

\begin{tabular}{cl}
\hline LA & Political Instability \\
\hline LA & Corruption \\
\hline LA & Practices of Competitors in the Informal Sector \\
\hline LA & Functioning of the Courts \\
\hline LA & Customs and Trade Regulations \\
\hline LA & Labor Regulations \\
\hline LA & Crime, Theft, and Disorder \\
\hline LA & Access to Land \\
\hline LA & Business Licensing and Permits \\
\hline LA & Tax Administration \\
\hline LA & Tax Rates \\
\hline LSR & Electricity \\
\hline LSR & Transportation \\
\hline LSR & Telecommunications \\
\hline LSR & Inadequately Educated Workforce \\
\hline HCF & Access to Financing \\
\hline LA stands for Low Appropriability; LSR stands for Low Social Returns; and HCF stands \\
for High Cost of Finance.
\end{tabular}

\section{A. The Data}

We use the 2010 Bolivian Enterprise Survey database published by the World Bank. It contains 312 observations at firm level (World Bank, 2007) from enterprises located in the three major cities of Bolivia: La Paz, Cochabamba and Santa Cruz. The sample includes formal small, medium, and large firms. Small Firms category represents firms with less than 19 workers, Medium Firms category represents those firms with 20 to 99 workers, and Large Firms category those firms with more than 100 workers. The ES is meant to be representative of the non-agricultural private sector economy, excluding firms with less than five employees (and excluding the informal sector). ${ }^{9}$ The strata for Enterprise Surveys are firm's size, business sector, and geographic region within a country.

\section{B. The Model}

We seek to rigorously determine whether firms' constraints differ between firm sizes. To achieve this goal, we specify a model for each one of the 16 potential obstacles. First, we will name a vector of constraint levels $Y_{1}^{*}$, which depends linearly on some matrix of explanatory (control) variables $X_{1}$ and a vector representing an ordinal measure of firm size $Y_{2}$.

\footnotetext{
9 "The sample is consistently defined in all countries and includes the entire manufacturing sector, the services sector, and the transportation and construction sectors. Public utilities, government services, health care, and financial services sectors are not included in the sample" (World Bank, 2007).
} 


$$
Y_{1}^{*}=\alpha\left[X_{1} \quad Y_{2}\right]+e_{1}
$$

Where $e_{1}$ is a vector of independent and identically distributed random variables, and $\alpha$ is a vector of coefficients to estimate. As we utilize a discrete measure of perceived constraints, we assume that each observed perception for any firm i $\left(y_{1, i}\right)$ is determined from a latent constraint level $\left(y_{1, i}^{*}\right)$ according to the following rule:

$$
y_{1, i}=\left\{\begin{array}{c}
0 \text { if } y_{1, i}^{*} \leq \gamma_{1} \\
1 \text { if } \gamma_{1} \leq y_{1, i}^{*} \leq \gamma_{2} \\
2 \text { if } \gamma_{2} \leq y_{1, i}^{*} \leq \gamma_{3} \\
3 \text { if } \gamma_{3} \leq y_{1, i}^{*} \leq \gamma_{4} \\
4 \text { if } \gamma_{4}<y_{1, i}^{*}
\end{array}\right.
$$

To verify whether firm size $Y_{2}{ }^{10}$ - after controlling by a set of regressors $X_{1}$ - determines the constraint level $Y_{1}^{11}$, we may solve the following log-likelihood function maximization problem (namely, an ordered probit). The transformation depends on the non-continuous form of the observed variable $Y_{1}$ according to the Limited Dependent Variable (LDV) literature.

$$
l(\alpha, \gamma)=\sum_{i=1}^{N} \sum_{j=0}^{4} \log \left(\operatorname{Pr}\left(y_{1, i}=j \mid x_{1, i}, y_{2, i}, \alpha, \gamma\right)\right) \cdot 1\left(y_{1, i}=j\right)
$$

where $j$ can take the values: $0=$ No Obstacle, $1=$ Minor Obstacle, $2=$ Moderate Obstacle, $3=$ Major Obstacle, $4=$ Very Severe Obstacle; $\mathrm{N}$ is the number of observations; the vector $X_{1}$ may consider variables that characterize firms and are intuitively exogenous, such as legal status of the firm, firm's industry or number of years of experience of the top manager. The vectors $\alpha$ and $\gamma$ will contain the coefficients and endogenous cut points to be estimated, respectively.

Note that we may estimate equation (3) coefficients and obtain consistent estimates if we could assure that observed firm size $Y_{2}{ }^{12}$ is not a result of firm's constraints (i.e. firm size is not caused by firm's constraints, or both are caused by some other third variable

${ }^{10}$ A continuous latent variable $Y_{2}^{*}$ has a correspondence with $Y_{2}$ according to a decision rule similar to that of equation (2).

${ }^{11}$ Where the constraint level may be any of the 16 obstacles we described above.

${ }^{12}$ Note that $y_{2, i}$, equivalently to $y_{1, i}$, is the observed firm size for the observation $i$. 
excluded/omitted from our specification). Thus, if we do not find evidence to consider firm's size as an endogenous regressor, we may simply estimate equation (3).

If we do find evidence to consider firm's size as an endogenous regressor we could estimate an IV-ordered probit model with an ordinal endogenous regressor (for $Y_{1}$ ). This means that equation (3) and equation (4) may instead be estimated jointly ${ }^{13}$ :

$$
\begin{gathered}
Y_{2}^{*}=\beta\left[\begin{array}{ll}
X_{1} & X_{2}
\end{array}\right]+e_{2} \\
l(\beta, \delta)=\sum_{i=1}^{N} \sum_{h=0}^{2} \log \left(\operatorname{Pr}\left(y_{2, i}=j \mid x_{1, i}, x_{2, i}, \beta, \delta\right)\right) \cdot 1\left(y_{2, i}=h\right)
\end{gathered}
$$

where, $\mathrm{h}$ can take the next values: $0=$ small enterprise, $1=$ medium enterprise, and $2=$ large enterprise. According to the instrumental variables literature, vector $X_{2}$ must consider variables that are correlated with the firm size but are independent of the analyzed obstacle $Y_{1}$ such as the formal/informal status of the firm when it began operations or the number of employees of the firm when it started operations. Analogously to equation (3), vectors $\beta$ and $\delta$ will contain estimated coefficients and cut points, respectively.

Our set of control variables $\left(X_{1}\right)$ includes: production sector, city, firm's current legal status, percent of the firm owned by the largest shareholder, principal owner's gender, origin of the investment financing needed to start the establishment, years of experience of the top manager, international-recognized quality certification status, and annual growth of labor (as a proxy to firm's performance). This set of variables was chosen based on data availability and its inclusion intends to reduce the possibility of biased estimators due to an omitted variable problem.

On the other hand, our potential instruments for the firm size variable or excluded exogenous variables $X_{2}$ are: i) the establishment belongs to a larger firm, ii) the number of full time employees when the establishment started operations, iii) the legal status of the firm when it started operations, iv) the age of the firm (number of years from firm creation). The set of excluded variables must be correlated with firm size but independent of firms' constraints perception; we believe the set that we choose satisfies that condition. In general, we expect that firms belonging to a larger firm (i.e. the surveyed establishment is part of a bigger firm)

${ }^{13}$ As Kawatsu and Largey (2009) note, one proof of the endogeneity of the variable $Y_{2}$ is found by testing the significance of the covariance of the errors from equations (3) and (4) (i.e. testing the significance of the reported athrho statistic which measures the Fisher's Z Transformation of the correlation between errors from both models). 
should be a characteristic quite independent of the obstacles they face, and correlated with firm size. The other mentioned instruments follow the past information rationale, that is, all of them were determined in the past, while obstacle perception is determined under current conditions. While the initial number of employees, initial legal status, and age of firms are related to the current firm size, they are not temporarily or rationally correlated with current constraints of firms. ${ }^{14}$

The IV ordered probit model with an ordinal endogenous regressor, represented above by equations (3) and (4), can be estimated considering a system of equations nested by the Conditional (Recursive) Mixed-Process Model (CMP). CMP is appropriate for two types of models: 1) those in which a truly recursive data-generating process is posited; and 2) those in which there is simultaneity, but instruments allow the construction of a recursive set of equations (as in two-stage least squares) that can be used to consistently estimate structural parameters in the final stage (see Roodman, 2009).

The CMP procedure calculates its estimators from a maximum likelihood approach over a multivariate normal distribution. With this novel procedure, we are able to take into account the potential endogeneity of a right-hand variable that is not continuous but dichotomous or polychotomous. In the next section we present the results of the model described above.

\section{RESULTS}

Our strategy is as follows: first, we estimate the system composed by equations (3) and (4) [IV-oprobit model], one for each of the 16 obstacles included in the database. If we cannot reject exogeneity test $\left(\mathrm{H}_{0}\right.$ : athrho=0) then we just estimate equation (3) alone [Oprobit model], which should provide consistent estimators. If we find evidence to reject exogeneity test, then it is more appropriate to estimate equations (3) and (4) jointly [IV-oprobit model]. ${ }^{15}$ However, we report both alternatives with their full results in the appendix. All estimations began by including the following set of control variables: geographic variables for each city where the survey was conducted; the industry to which the firm belongs; legal status and ownership structure of firms; firm performance (annual labor growth in the last three years); and other characteristics mentioned earlier, such as the principal owner's gender, years of experience of the top manager, and internationally-recognized quality certification. Only those regressors with statistically significant coefficients were included in the final specification. Second, we report marg+inal effects and conditional probabilities of the most appropriate model, which permit us to reach our twofold objective: verify if obstacles are not equal between different firm sizes, and identify the most binding constraints.

\footnotetext{
${ }^{14}$ The relevance of our excluded instruments depends on overidentification and underdentification tests, they are reported in the Appendix. See next footnote for a further clarification.

${ }^{15}$ There is not a known method to calculate the over-identification test for this kind of models. Therefore, only for reference purposes, we report this test, and the under-identification test for the same specifications reported using an instrumental variable ML estimator for an endogenous continuous structural variable $\left(\mathrm{Y}_{1}\right)$ and an endogenous continuous regressor $\left(\mathrm{Y}_{2}\right)$. See appendix.
} 


\section{A. Firms Constraints: Does Firm Size Matter?}

Table 3 summarizes the model selection process, and the main qualitative results about the effect of firm size ${ }^{16}$ :

Table 3. Summary of Model Selection Process

\begin{tabular}{lcc}
\hline \multicolumn{1}{c}{ CONSTRAINT } & $\begin{array}{c}\text { Endogeneity } \\
\text { Issue? }^{\text {a }}\end{array}$ & $\begin{array}{c}\text { Does Size } \\
\text { Matter }^{\text {b }}\end{array}$ \\
\hline \hline ACCESS TO FINANCING & YES & YES \\
\hline ACCESS TO LAND & NO & NO \\
\hline BUSINESS LICENSING AND PERMITS & YES & YES \\
\hline CORRUPTION & NO & NO \\
\hline CRIME THEFT AND DISORDER & NO & NO \\
\hline CUSTOMS AND TRADE REGULATION & NO & NO \\
\hline ELECTRICITY & YES & YES \\
\hline FUNCTIONING OF THE COURTS/COURTS & NO & YES \\
\hline INADEQUATELY EDUCATED WORKFORCE & NO & NO \\
\hline LABOR REGULATIONS & NO & NO \\
\hline POLITICAL INSTABILITY & NO & NO \\
\hline PRACTICES OF COMPETITORS IN THE INFORMAL SECTOR & YES & YES \\
\hline TAX ADMINISTRATION & NO & YES \\
\hline TAX RATES & NO & YES \\
\hline TELECOMMUNICATIONS & YES & YES \\
\hline TRANSPORTATION & YES & YES \\
\hline \hline a.Yes: Reject HO: Athrho $=0$ when estimating (3) and (4) jointly. & & \\
b.Yes: At least one coefficient associated to firm size is statistically significant in the "right" model.
\end{tabular}

The results in Table 3 show that 9 out of 16 obstacles are perceived with different intensity depending on the firm size (last column); those results belong to the more adequate model ("right" model) according to our analysis. ${ }^{17}$ Moreover, there is evidence of a potential endogeneity issue in 6 cases. In addition, Table 4 shows the conditional probability of occurrence for each classification of intensity for each potential obstacle. The top 4 probabilities for each intensity classification (No Obstacle [0], Minor Obstacle [1], Moderate Obstacle [2], Major Obstacle [3], and Very Severe Obstacle [4]) are reported in bold font. For example, the probability that an average firm considers 'Electricity' as a very severe obstacle for its functioning is 27 percent, while probability, for a representative firm, of 'Access to Land' representing no obstacle is 45 percent. Table 4 allows us to identify which obstacles we should be more concerned about, and which ones are not so problematic. The model results show that 'Electricity','Practices of Competitors in the Informal Sector,' 'Transportation,' and 'Corruption' are most likely very severe obstacles to firms, while

${ }^{16}$ We assume that size matters when at least one of the associated coefficients to firm size is statistically significant at $5 \%$.

${ }^{17}$ The "right" model corresponds to the estimation of Eq. (3) when there is no evidence of endogeneity of the firm size variable; otherwise, it corresponds to the joint estimation of the system composed by Eq. (3) and (4). 
'Access to land', 'Customs and Trade Regulations', 'Telecommunications', and 'Access to Financing', might be considered as minor issues, since they show a larger likelihood of representing no obstacle to firms.

Table 4. Model Results: Predicted Probability for a Representative Firm

\begin{tabular}{|c|c|c|c|c|c|}
\hline CONSTRAINT & $\operatorname{Pr}(\mathrm{Y} 1=0)$ & $\operatorname{Pr}(\mathrm{Y} 1=1)$ & $\operatorname{Pr}(\mathrm{Y} 1=2)$ & $\operatorname{Pr}(\mathrm{Y} 1=3)$ & $\operatorname{Pr}(\mathrm{Y} 1=4)$ \\
\hline ACCESS TO FINANCING & $26 \%$ & $10 \%$ & $38 \%$ & $22 \%$ & $4 \%$ \\
\hline ACCESS TO LAND & $45 \%$ & $19 \%$ & $24 \%$ & $11 \%$ & $1 \%$ \\
\hline BUSINESS LICENSING AND PERMITS & $17 \%$ & $37 \%$ & $38 \%$ & $7 \%$ & $1 \%$ \\
\hline CORRUPTION & $9 \%$ & $13 \%$ & $16 \%$ & $46 \%$ & $16 \%$ \\
\hline CRIME THEFT AND DISORDER & $12 \%$ & $18 \%$ & $25 \%$ & $31 \%$ & $15 \%$ \\
\hline CUSTOMS AND TRADE REGULATION & $35 \%$ & $18 \%$ & $35 \%$ & $11 \%$ & $1 \%$ \\
\hline ELECTRICITY & $22 \%$ & $26 \%$ & $13 \%$ & $12 \%$ & $27 \%$ \\
\hline FUNCTIONING OF THE COURTS/COURTS & $23 \%$ & $18 \%$ & $27 \%$ & $26 \%$ & $6 \%$ \\
\hline INADEQUATELY EDUCATED WORKFORCE & $4 \%$ & $20 \%$ & $43 \%$ & $25 \%$ & $8 \%$ \\
\hline LABOR REGULATIONS & $4 \%$ & $22 \%$ & $48 \%$ & $22 \%$ & $4 \%$ \\
\hline POLITICAL INSTABILITY & $7 \%$ & $18 \%$ & $26 \%$ & $37 \%$ & $12 \%$ \\
\hline PRACTICES OF COMPETTTORS IN THE INFORMAL SECTOR & $7 \%$ & $7 \%$ & $38 \%$ & $28 \%$ & $20 \%$ \\
\hline TAX ADMINISTRATION & $20 \%$ & $22 \%$ & $54 \%$ & $3 \%$ & $1 \%$ \\
\hline TAX RATES & $20 \%$ & $23 \%$ & $50 \%$ & $5 \%$ & $2 \%$ \\
\hline TELECOMMUNICATIONS & $29 \%$ & $16 \%$ & $24 \%$ & $17 \%$ & $15 \%$ \\
\hline TRANSPORTATION & $20 \%$ & $22 \%$ & $28 \%$ & $12 \%$ & $17 \%$ \\
\hline
\end{tabular}

However, the results presented so far do not take into account differences by firm size. The following graphs, reporting marginal effects, show differences between firm sizes in an illustrative manner. Note that marginal effects of firm size are calculated considering a change from a small-firm category to medium or large firm (i.e. small firm is the pivot category). In the following - based on results from the 'right' model—we focus only on those obstacles where firm size matters statistically (see Table 3 for the detail).

Figure 8. Electricity: Marginal Effects of Firm Size (for discrete change of dummy variable from 0 to 1 )

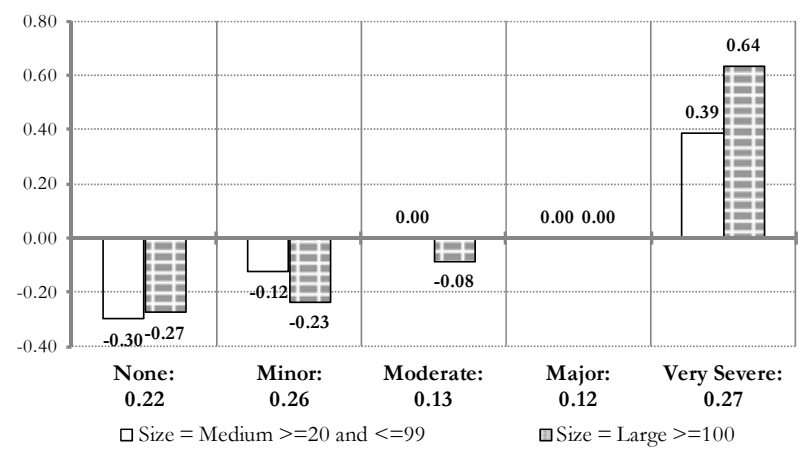

Figure 8 shows that 'Electricity' representing a very severe obstacle is a more likely outcome for medium and large firms; the marginal effect for a large firm is 0.64 , while it is 0.39 for medium firms. In a consistent manner, medium and large firms are less likely to consider 'Electricity' provision as no obstacle; marginal effect for a large firm is -0.27 , and -0.30 for 
medium firms. Figure 8 also reports the predicted probability calculated at the mean value of the explicative variables. ${ }^{18}$ For instance, the model predicts - for a representative firm - that 'Electricity' would be considered as no obstacle with 22 percent likelihood; on the other hand, a representative firm will face a 27 percent probability of considering 'Electricity' as a very severe obstacle. These results suggest that provision of public infrastructure, such as 'Electricity', is an important concern for all firms, but especially relevant for medium and large firms.

Figure 9. Telecommunications: Marginal Effects of Firm Size (for discrete change of dummy variable from 0 to 1 )

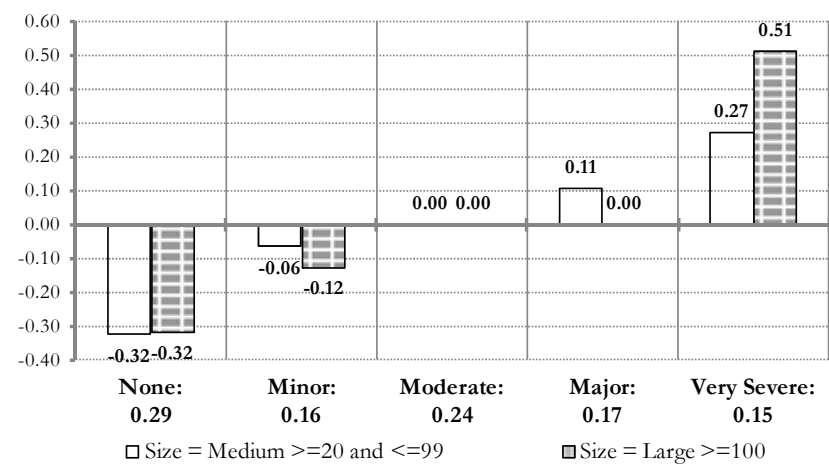

Results on 'Electricity' are very similar to those of 'Telecommunications,' as Figure 9 shows. The expected likelihood of 'Telecommunications' representing a very severe obstacle is 15 percent but it increases when we refer to medium or large firms. (Accordingly, the expected probability of 'Telecommunications' representing no obstacle for firms ( 29 percent) decreases when we refer to medium and large firms.) These results highlight that provision of public infrastructure, such as 'Telecommunications', is an important concern for all firms, but especially relevant for medium and large firms. Note that the expected probability of 'Electricity' representing a major or very severe obstacle is about 40 percent, while the same probability for 'Telecommunications' obstacle is about 33 percent, suggesting that we might look for public policies focused on improving these elements, since we know that they would benefit medium and large firms' performance.

${ }^{18}$ Below the $\mathrm{X}$ axis, Figures 7-15 show the predicted probability associated with the 5 possible outcomes (None, Minor, Moderate, Major, Severe) when evaluating the model at their average values, thus they correspond to the probabilities of a representative firm. 
Figure 10. Transportation: Marginal Effects of Firm Size (for discrete change of dummy variable from 0 to 1 )

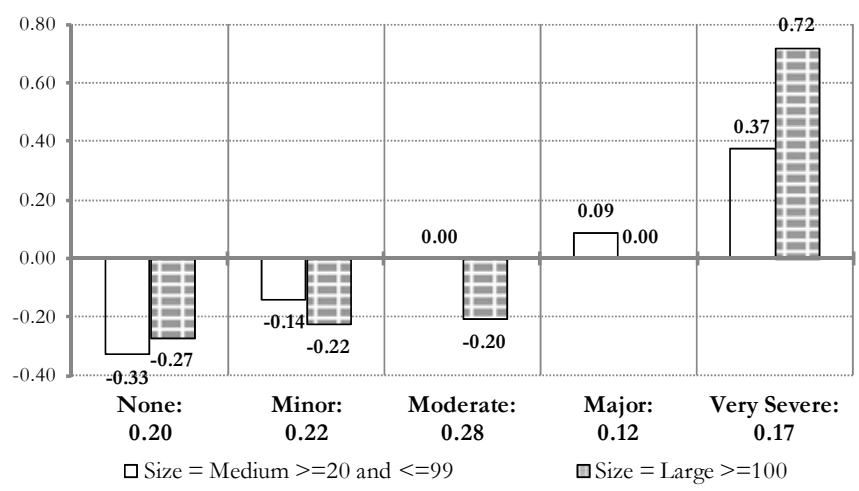

When analyzing 'Transportation' as an obstacle, results shown in Figure 10 suggest that firm size matters; indeed, continuing our marginal effect analysis, it seems that 'Transportation' will also represent more trouble for medium and large firms. This seems reasonable considering that small firms may not depend on transportation systems as much as large firms (which could be exporters or importers). In any case, the expected probability of facing a major or very severe obstacle - for a representative firm - is slightly smaller than in the first two obstacles analyzed (30 percent).

Figure 11. Practices of Competitors in the Informal Sector: Marginal Effects of Firm Size (for discrete change of dummy variable from 0 to 1 )

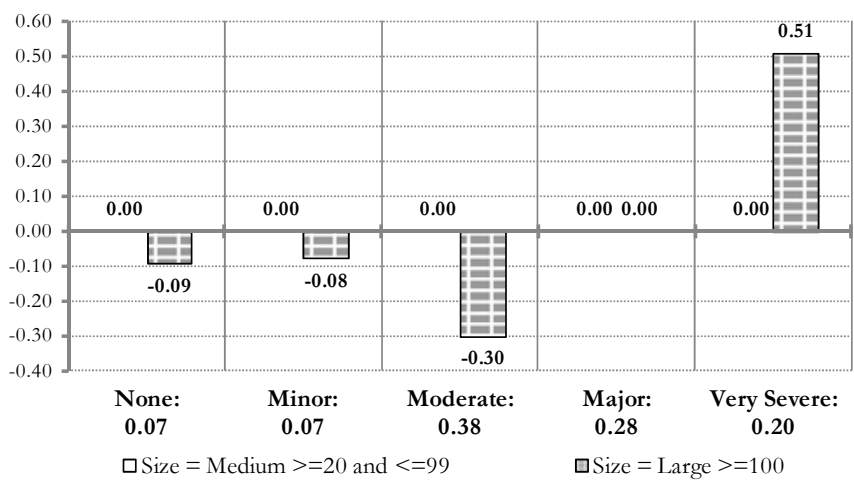

Results concerning 'Practices of Competitors in the Informal Sector' confirm some stylized facts we saw before. It is clear that the expected probability of representing no obstacle is small (7 percent), while the expected probability of representing a major or very severe obstacle is very high (48 percent), both for a representative firm. We also notice that the likelihood of facing a very severe obstacle increases when we are talking about a large firm. These results confirm what we saw in section 3, Table 1: informality represents the most important obstacle for Bolivian large firms. Although large firms face more trouble because of informal markets, our results indicate that informality is a generalized problem for all firms. 
Figure 12. Courts: Marginal Effects of Firm Size (for discrete change of dummy variable from 0 to 1 )

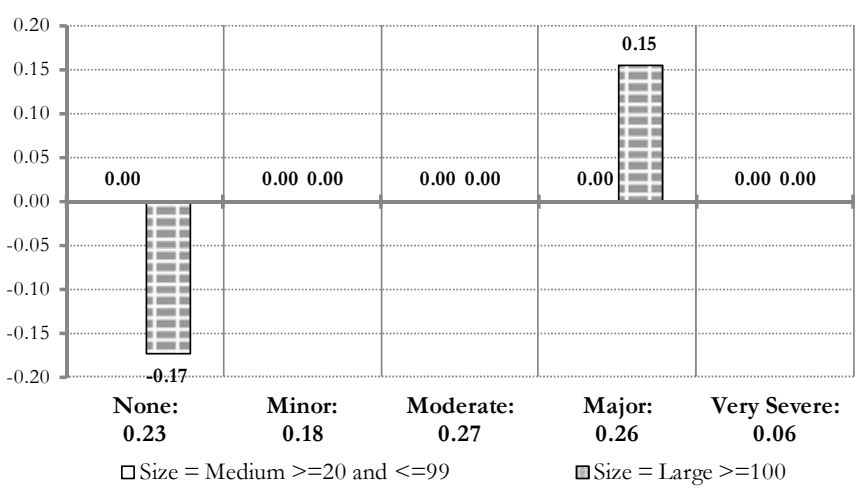

In the same manner, while the expected likelihood of 'Functioning of Courts' representing a major or very severe obstacle for firms is 33 percent, Figure 12 results suggest that it could be even a bigger problem for large firms. In fact, a large firm would face a larger likelihood of considering it as a major obstacle (marginal effect of $0.15 \mathrm{pp}$ ), and a smaller likelihood of representing no obstacle (a negative marginal effect of $0.17 \mathrm{pp}$ )

Figure 13. Tax Rates: Marginal Effects of Firm Size (for discrete change of dummy variable from 0 to 1 )

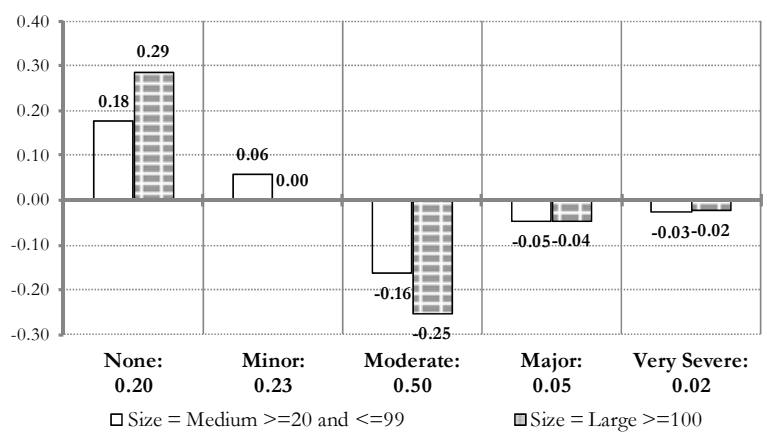

Figure 14. Tax Administration: Marginal Effects of Firm Size (for discrete change of dummy variable from 0 to 1 )

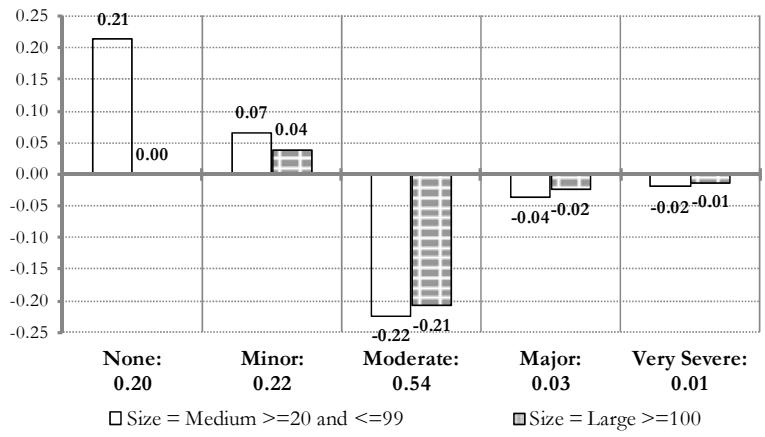


While the obstacles described in Figures 8-12 were relatively important for all firms no matter their size, Figures 13 and 14 show two obstacles that probably would not be considered as binding constraints, even though firm size matters when trying to understand them. 'Tax Rates' and 'Tax Administration' show smaller probabilities of being considered as major or very severe obstacles, in fact, those probabilities are 7 percent and 4 percent, respectively. Results also suggest that large or medium firm will face a larger likelihood of considering 'Tax Rates' as no obstacle.

Figure 15. Business Licensing and Permits: Marginal Effects of Firm Size (for discrete change of dummy variable from 0 to 1 )

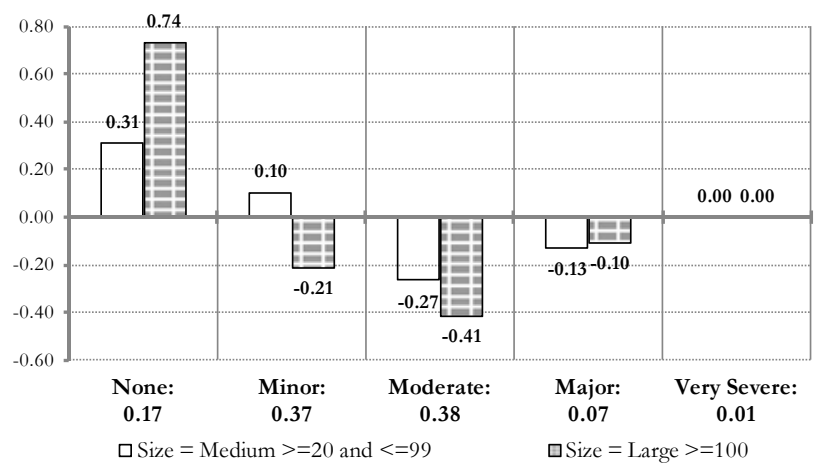

The 'Business Licensing and Permits' obstacle represents just a minor or moderate issue for firms also. According to Figure 15, the expected probability of representing a major or very severe obstacle is 7 percent. In addition, it is interesting to note that large and medium firms face a slightly smaller likelihood of facing a major problem, while they have a higher likelihood of facing no obstacle. Thus, large and medium firms are in better position when we refer to 'Business Licensing and Permits' obstacles. This result seems natural since 'Business Licensing and Permits' may be considered a starting business activity, which would be associated more strongly with small firms.

Figure 16. Access to Financing: Marginal Effects of Firm Size (for discrete change of dummy variable from 0 to 1 )

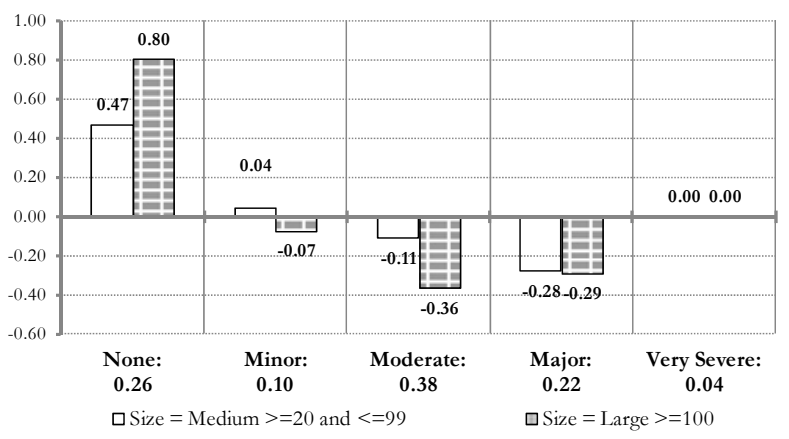


Finally, let us describe findings about the 'Access to Financing' obstacle. Results from Figure 16 are very similar to those from Figure 15. 'Access to Financing' does not seem to represent a very severe obstacle for a representative firm (likelihood is just 4 percent), but it seems there is a reasonable probability of representing a major problem (22 percent). Moreover, there is some evidence to distinguish a quantitative difference between different firm sizes, as medium and large firms would expect a larger likelihood of facing no obstacle than small firms. This is confirmed by noting that medium and large firms are less likely to consider 'Access to Finance' as a major obstacle, while implicitly, small firms would face a higher probability for the 'major or very severe obstacle' outcome.

\section{B. Binding Constraints}

As mentioned earlier, our estimations are useful to analyze quantitatively the most important constraints. Specifically, we propose two alternative measures to rank the worst obstacles (or most binding constraints) faced by firms according to their size:

- Naturally, the first measure reports the conditional probability for expecting a major or very severe obstacle by obstacle and by firm size. This seems the most straightforward way to state a ranking of worst obstacles.

- Our second measure has a different meaning. It quantifies how severe is the effect of firm size on a specific obstacle, thus it must be jointly interpreted with the first measure we described above. For medium firms, we calculate the sum of marginal effects of facing major and very severe obstacles with respect to the pivot category: small firm (i.e. how much being a medium firm increases likelihood of facing obstacles). The larger is this sum, the more severe is the effect of firm size and the more likely this obstacle is a problem just for medium firms. The same metric and interpretation applies for large firms. On the other hand, for small firms, we calculate the sum of medium and large firms' marginal effects for facing major and very severe obstacles. The smaller is this sum, the less severe is the effect of firm size and the obstacle is less likely to represent a particular problem for small firms.

Table 5, and Figures 17 and 18, show results for the first measure. We report conditional probability for expecting a major or very severe obstacle. The ranking confirms that 'Corruption', 'Crime, Theft and Disorder', 'Informality' and 'Political Instability' seem to be common obstacles to all firms. Furthermore, it appears that public services provision would be a problem for medium and large firms ('Electricity', 'Transportation', and 'Telecommunications'). Another point worth mentioning is that 'Access to Financing' would be an important obstacle only for small firms (likelihood of representing a major or very severe obstacle is 59 percent for small firms, 12 percent for medium firms, and just close to 0 percent for large firms). 
Table 5. Ranking of Conditional Probabilities for Expecting a Major or Very Severe Obstacles (by firm size)

\begin{tabular}{|c|c|c|c|c|c|}
\hline \multicolumn{2}{|l|}{ Very Small + Small Firms } & \multicolumn{2}{|l|}{ Medium } & \multicolumn{2}{|l|}{ Large } \\
\hline Corruption & 0.63 & Electricity & 0.59 & Practices of Comp. in Informal Sector & 0.87 \\
\hline Access to Finanding & 0.59 & Corruption & 0.59 & Electricity & 0.83 \\
\hline Crime, Theft, and Disorder & 0.54 & Transportation & 0.53 & Transportation & 0.82 \\
\hline Political Instability & 0.45 & Telecommunications & 0.51 & Political Instability & 0.71 \\
\hline Practices of Comp. in Informal Sector & 0.38 & Practices of Comp. in Informal Sector & 0.50 & Telecommunications & 0.69 \\
\hline Inadequately Educated Workforce & 0.37 & Political Instability & 0.48 & Corruption & 0.68 \\
\hline Functioning of the Courts & 0.24 & Functioning of the Courts & 0.39 & Functioning of the Courts & 0.52 \\
\hline Labor Regulations & 0.24 & Crime, Theft, and Disorder & 0.35 & Crime, Theft, and Disorder & 0.44 \\
\hline Business Licensing and Permits & 0.23 & Inadequately Educated Workforce & 0.27 & Labor Regulations & 0.41 \\
\hline Electricity & 0.19 & Labor Regulations & 0.25 & Inadequately Educated Workforce & 0.33 \\
\hline Telecommunications & 0.15 & Access to Finanding & 0.12 & Customs and Trade Regulations & 0.25 \\
\hline Customs and Trade Regulations & 0.12 & Customs and Trade Regulations & 0.10 & Access to Land & 0.18 \\
\hline Access to Land & 0.12 & Access to Land & 0.09 & Tax Rates & 0.02 \\
\hline Tax Rates & 0.12 & Tax Rates & 0.04 & Tax Administration & 0.02 \\
\hline Transportation & 0.10 & Business Licensing and Permits & 0.03 & Access to Finanding & 0.00 \\
\hline Tax Administration & 0.08 & Tax Administration & 0.02 & Business Licensing and Permits & 0.00 \\
\hline
\end{tabular}

Figures 17 and 18 reinforce the Table 5 results by showing conditional probabilities for four categories of firms: Average, Small, Medium, and Large ("Average" refers to a representative firm in Bolivia, being a weighted average of small, medium, and large firms).Visually, darker histograms reflect 'major obstacles' predominance, while lighter histograms represent 'minor' or 'no obstacle' predominance. It is important to highlight that unconditional likelihoods presented in Section 2 can be very different from the conditional likelihoods presented here; we show a comparison of both measures in Appendix C, which demonstrate that simple bivariate descriptive statistics may not be sufficient for a formal analysis on the firm size-firm constraint relationship.

Figure 17. Level of Obstacle to the Functioning of the Establishment (Conditional Probability)
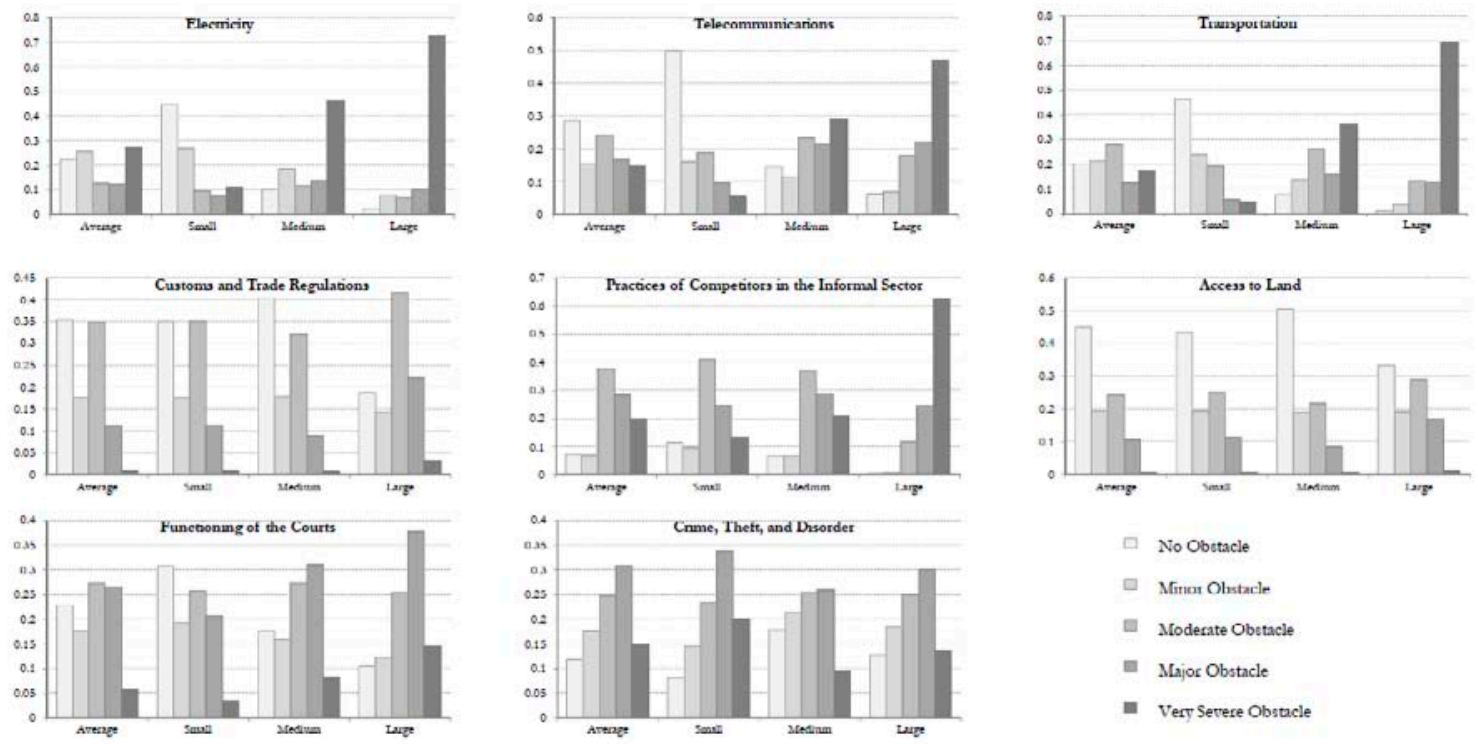

No Obotacle

ㅁ.mon Olstacle

- Modecate Obstacle

- Major Obstacle

- Very Severe Obstacle 
Figure 18. Level of Obstacle to the functioning of the establishment (Conditional Probability)
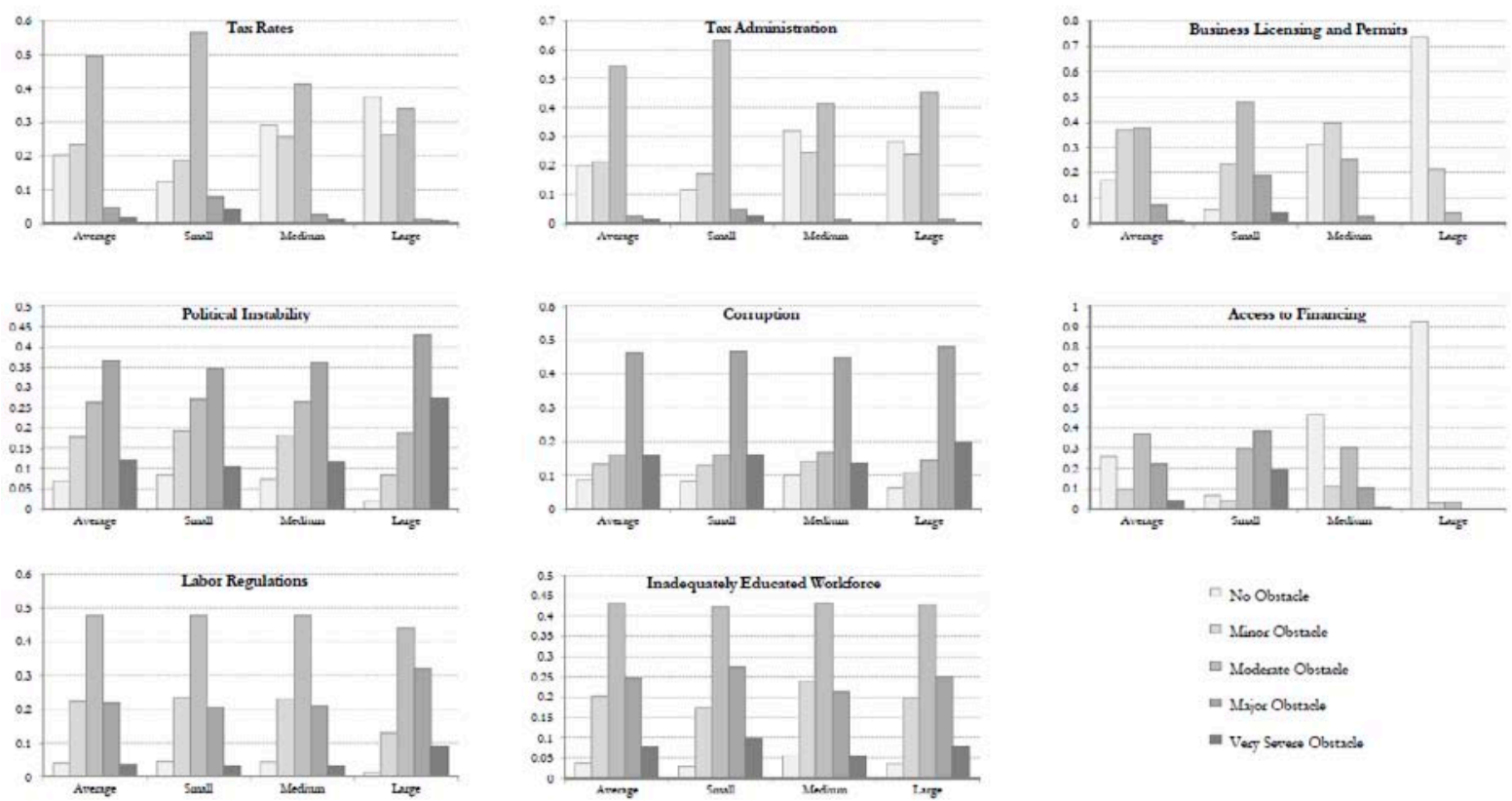

With regard to our second measure, Table 6 summarizes the most harmful obstacles by firm size categories (i.e. it shows a measure for the strength of firm-size differences). For instance, 'Access to Financing' appears to be more troublesome for small firms relative to other firm sizes. As described above, we ranked our findings according to a score, for example, the 'Access to Financing' obstacle score is -0.57 , which is the sum of marginal effects of facing a major or very severe obstacle for medium $(-0.28)$ and large firms $(-0.27)$. The negative sign means that medium and large firms would expect a smaller likelihood of facing a major or very severe obstacle, thus, small firms are in a worse position than medium and large ones.

Table 6. Ranking of Relative Worst Obstacles by Firm Size

\begin{tabular}{lrr}
\multicolumn{2}{c}{ Worst Obstacles by Firm Size } & \\
\hline \hline Access to Financing & Small Firms & -0.57 \\
\hline Business Licensing and Permits & -0.23 \\
\hline Tax Rates & -0.14 \\
\hline Tax Administration & Medium Firms & -0.09 \\
\hline \hline Transportation & & 0.46 \\
\hline Electricity & Large Firms & 0.39 \\
\hline Telecommunications & 0.38 \\
\hline & & 0.72 \\
\hline \hline Transportation & 0.64 \\
\hline Electricity & 0.51 \\
\hline Telecommunications & 0.51 \\
\hline Practices of Competitors in the Informal Sector
\end{tabular}


The metric for medium and large firms is even easier to calculate. For instance, the score associated with 'Transportation' (0.46) is just the sum of marginal effects of facing a major or very severe obstacle. In this case, being a medium firm increases the likelihood of facing a major obstacle in 0.09 , while it increases the likelihood of facing a very severe obstacle in 0.37. It is worth noting that small firms seem to face more issues with starting business categories, and they are more sensitive to tax rates and tax administration. On the other hand, medium and large firms face more issues with infrastructure variables (transportation, electricity and telecommunications), and large firms seem concerned more about 'Practices of competitors in the informal sector.'

Note that results from our second measure do not imply that public policy should be oriented only to the obstacles shown in Table 6; indeed, public policy should take into account that 'Practices of Competitors in the Informal Sector', 'Political Instability', and 'Corruption' are generalized problems, while considering - at the same time-that some obstacles could represent problems to particular firm sizes.

\section{CONCLUDING REMARKS}

In this paper, we generate evidence on two issues: Do constraints faced by firms have varying intensities according to firm size? And, which are the most binding constraints to firm performance in Bolivia?

Using the World Bank Enterprise Survey 2010 for Bolivia, we construct unconditional and conditional likelihoods for being constrained, considering three categories of firm size. Importantly, we argue that endogeneity between firms' constraints and firm size should be considered when estimating the conditional probabilities. We find that conditional likelihoods can be quite different from their unconditional counterparts, confirming that the effort to control for other variables is important and contributes to a more accurate understanding of binding constraints.

Based on the conditional estimates, our results distinguish two sets of binding constraints: (i) those that are common to all sizes of firms, and (ii) those that affect more strongly a subset of firms according to their size. Regarding the first set, our estimations show that Bolivian firms face common binding constraints in terms of 'Corruption', 'Political Instability', and 'Crime, Theft and Disorder'; there is no evidence of firm size effect related with those constraints.

However, there is a subset of binding constraints whose effects differ between firm sizes: 'Practices of Competitors in the Informal Sector', 'Access to Financing', 'Electricity', 'Transportation', and 'Functioning of Courts.' Our results suggest that large firms are more sensitive to Informal Sector activities than medium and small firms. Something similar occurs with 'Electricity', 'Transportation', and 'Functioning of Courts', which seem to negatively influence more strongly large and medium firms. On the other hand, 'Access to Financing' is a binding constraint only for small firms. 
Viewed in the framework and terminology of the Hausmann-Rodrik-Velasco growth diagnostics approach, our results suggest that the various obstacles associated with 'Low Appropriability' would be common to all firms; while obstacles associated with 'Low Social Returns' (especially lack of infrastructure) would mainly constrain medium and large firms, and constraints associated with 'High Cost of Finance' would most affect small firms' performance. However, an advantage of our approach, which is able to draw on the detailed firm survey data for 16 potential obstacles, is that it provides a more specific identification of particular obstacles to the functioning of firms.

Indeed, our findings are important because they can inform the prioritization of policy reform efforts. Identification of the most binding constraints should allow policies to support a better resource allocation, which should be reflected in increasing investment returns, employment and growth. 


\section{REFERENCES}

Angelini, P. and A. Generale, 2005, "Firm Size Distribution: Do Financial Constraints Explain it All? Evidence from Survey Data," Bank of Italy Temi di Discussione, Working Paper No. 549, Available via the Internet: http://ssrn.com/abstract=1015094.

Ardagna, S., and A. Lusardi, 2008, "Explaining International Differences in Entrepreneurship: The Role of Individual Characteristics and Regulatory Constraints," NBER Working Paper No. 14012 (Cambridge, Massachusetts: National Bureau of Economic Research).

Aterido, R., M. Hallward-Driemeier, and C. Pages, 2009, "Big Constraints to Small Firms' Growth? Business Environment and Employment Growth Across Firms," Policy Research Working Paper Series 5032 (Washington: World Bank).

Beck, T., A. Demirgüç-Kunt, and V. Maksimovic, 2005, "Financial and Legal Constraints to Growth: Does Firm Size Matter?" Journal of Finance, Vol. 60, No. 1, pp. 137-77.

Bernardt, Y., and R. Muller, 2000, "Determinants of Firm Size-A Survey of Literature," Research Report 9913/A, EIM Business \& Policy Research, The Netherlands.

Cabral, L.M.B., and J. Mata, 2003, "On the Evolution of the Firm Size Distribution: Fact and Theory," American Economic Review, Vol. 93, No. 4, pp. 1075-90.

Calvo, Sara, 2006, "Applying the Growth Diagnostics Approach: the Case of Bolivia," (Washington: World Bank).

Canton, E., L. Grilo, J. Monteagudo, and P. van der Zwan, "Investigating the Perceptions of Credit Constraints in the European Union," ERS 2010, No 1.

Clementi, G.L., and H.A. Hopenhayn, 2006, “A Theory of Financing Constraints and Firm Dynamics," Quarterly Journal of Economics, Vol. 121, Issue 1, pp. 229-65.

Cooley, T., and V. Quadrini, 2001, "Financial Markets and Firm Dynamics," American Economic Review, Vol. 91, No. 5, pp. 1286-1310.

Dinh, Hinh T., D. Mavridis, and H. Nguyen, 2010, “The Binding Constraint on Firms' Growth in Developing Countries," World Bank Policy Research Working Paper Series (Washington: World Bank).

Fagiolo, G., and A. Luzzi, 2006, "Do Liquidity Constraints Matter in Explaining Firm Size and Growth? Some Evidence from the Italian Manufacturing Industry," Industrial and Corporate Change, Vol. 15, No. 1, pp. 1-39. 
Greenwald, B., and J. Stiglitz, 1993, "Financial Markets Imperfections and Business Cycles," Quarterly Journal of Economics, Vol. 108, No. 1, pp. 77-114.

Halabí, C., and R. Lussier, 2010, “A Model for Predicting Small Firm Performance: Increasing the Probability of Entrepreneurial Success," Documentos de Trabajo 03, Universidad Diego Portales, Chile.

Hausmann, R., B. Klinger, and R. Wagner, 2008, “Doing Growth Diagnostics in Practice: A 'Mindbook'," CID Working Paper No. 177, September.

Hausmann, R., D. Rodrik, and A. Velasco, 2005, "Growth Diagnostics," John F. Kennedy School of Government (Cambridge, Massachusetts: Harvard University).

Hobdari, B., D.C. Jones, and N. Mygind, 2009, "Capital Investment and Determinants of Financial Constraints in Estonia," Economic Systems, Vol. 33, No. 4, Available via the Internet: http://ssrn.com/abstract=1517309.

Holtz-Eakin, D., D. Joulfaian, and H.S. Rosen, 1994, "Entrepreneurial Decisions and Liquidity Constraints," The RAND Journal of Economics, Vol. 25, No. 2, pp. 334-47.

Hurst E., and A. Lusardi, 2004, "Liquidity Constraints, Households, and Entrepreneurship," Journal of Political Economy, Vol. 112, No. 2, pp. 319-47.

Johansson, Edvard, 2000, "Self-Employment and Liquidity Constraints: Evidence from Finland," Scandinavian Journal of Economics," Vol. 102, No. 1, pp. 123-34.

Kawakatsu, H., and A.G. Largey, 2009, "EM Algorithms for Ordered Probit Models with Endogenous Regressors," Econometrics Journal, Vol. 12, Issue 1, pp. 164-86. Available via the Internet: http://ssrn.com/abstract=1376058.

Kounouwewa, J., and D. Chao, 2011, "Financing Constraints Determinants in African Countries," International Journal of Applied Economics and Finance 5 (1), pp. $30-45$.

Kumar, A., and M. Francisco, 2005, "Entreprise Size, Financing Patterns, and Credit Constraints in Brazil," World Bank Working Paper No. 49 (Washington DC: World Bank).

Kumar, K.B., R.G. Rajan, and L. Zingales, 1999, "What Determines Firm Size?” Working Paper 7208 (Cambridge, Massachusetts: National Bureau of Economic Research).

Pagan, O. P., and F. Schivardi, 2003, "Firm Size Distribution and Growth," Scandinavian Journal of Economics, Vol. 105, No. 2, pp. 255-74. 
Parker, S., and M. van Praag, 2005, "Schooling, Capital Constraints and Entrepreneurial Performance," Tinbergen Institute Discussion Paper, TI 2004-106/3.

Roodman, D., 2009, "Estimating Fully Observed Recursive Mixed-Process Models with cmp," Working Paper 168 (Washington DC: Center for Global Development).

Schiantarelli, F., 1995, "Financial Constraints and Investment: A Critical Review of Methodological Issues and International Evidence," in Is Bank Lending Important for the Transmission of Monetary Policy? ed. by L. Peek and E. Rosengren (Boston: Federal Reserve Bank).

World Bank, 2007, “Enterprise Surveys Bolivia: Country Profile 2006,” Enterprise Analysis Unit. 


\section{Appendix I}

\section{Proportion of Firms that Identify None, and Major or Severe Levels of Obstacles (By Firm Size)}

Level of Obstacle of ELECTRICITY to the functioning of the establishment

\begin{tabular}{|c|c|c|c|c|}
\hline & $\begin{array}{c}\text { Small }<= \\
19 \\
\end{array}$ & $\begin{array}{c}\text { Medium } \\
>=20 \text { and }<=99\end{array}$ & $\begin{array}{r}\text { Large }> \\
=100 \\
\end{array}$ & Total \\
\hline None & $\begin{array}{r}0.313 \\
{[0.170,0.503]} \\
\end{array}$ & $\begin{array}{r}0.207 \\
{[0.102,0.376]} \\
\end{array}$ & $\begin{array}{c}0.41 \\
{[0.149,0.733]}\end{array}$ & $\begin{array}{r}0.282 \\
{[0.184,0.406]} \\
\end{array}$ \\
\hline Major or very sever & $\begin{array}{lr}\text { e } & 0.375 \\
{[0.221,0.559]}\end{array}$ & $\begin{array}{r}0.368 \\
{[0.204,0.569]}\end{array}$ & $\begin{array}{c}0.421 \\
{[0.193,0.688]}\end{array}$ & $\begin{array}{r}0.376 \\
{[0.266,0.501]}\end{array}$ \\
\hline $\mathrm{N}$ & 362 & & & \\
\hline
\end{tabular}

Level of Obstacle of TELECOMMUNICATIONS to the functioning of the establishment

\begin{tabular}{|c|c|c|c|c|}
\hline & $\begin{array}{c}\text { Small }<= \\
19 \\
\end{array}$ & $\begin{array}{c}\text { Medium } \\
>=20 \text { and }<=99 \\
\end{array}$ & $\begin{array}{r}\text { Large }> \\
=100 \\
\end{array}$ & Total \\
\hline \multirow[t]{2}{*}{ None } & 0.371 & 0.247 & 0.443 & 0.33 \\
\hline & {$[0.216,0.559]$} & {$[0.116,0.449]$} & {$[0.177,0.746]$} & {$[0.222,0.460]$} \\
\hline \multirow[t]{2}{*}{ Major or very sever } & 0.32 & 0.36 & 0.259 & 0.329 \\
\hline & {$[0.184,0.494]$} & {$[0.204,0.552]$} & {$[0.113,0.490]$} & {$[0.230,0.447]$} \\
\hline $\mathrm{N}$ & 360 & & & \\
\hline
\end{tabular}

Level of Obstacle of TRANSPORTATION to the functioning

\begin{tabular}{|c|c|c|c|c|}
\hline & $\begin{array}{l}\text { Small }<= \\
19\end{array}$ & $\begin{array}{c}\text { Medium } \\
>=20 \text { and }<=99\end{array}$ & $\begin{array}{l}\text { Large }> \\
\quad=100\end{array}$ & Total \\
\hline None & $\begin{array}{r}0.284 \\
{[0.146,0.479]}\end{array}$ & $\begin{array}{r}0.169 \\
{[0.061,0.387]}\end{array}$ & $\begin{array}{c}0.0626 \\
{[0.025,0.149]}\end{array}$ & $\begin{array}{r}0.219 \\
{[0.128,0.348]}\end{array}$ \\
\hline Major or very sever & $\begin{array}{l}0.279 \\
0.153,0.452]\end{array}$ & $\begin{array}{r}0.343 \\
{[0.190,0.539]}\end{array}$ & $\begin{array}{c}0.268 \\
{[0.120,0.496]}\end{array}$ & $\begin{array}{r}0.302 \\
{[0.207,0.419]}\end{array}$ \\
\hline $\mathrm{N}$ & 356 & & & \\
\hline \multicolumn{5}{|c|}{$\begin{array}{l}\text { Level of Obstacle of CUSTOMS AND TRADE REGULATION } \\
\text { to the functioning of the establishment }\end{array}$} \\
\hline & $\begin{array}{l}\text { Small }<= \\
19\end{array}$ & $\begin{array}{c}\text { Medium } \\
>=20 \text { and }<=99\end{array}$ & $\begin{array}{c}\text { Large }>= \\
100\end{array}$ & Total \\
\hline None & $\begin{array}{r}0.44 \\
{[0.273,0.622]}\end{array}$ & $\begin{array}{r}0.331 \\
{[0.158,0.566]}\end{array}$ & $\begin{array}{r}0.181 \\
{[0.068,0.401]}\end{array}$ & $\begin{array}{r}0.374 \\
{[0.258,0.508} \\
\end{array}$ \\
\hline Major or very sever & $\begin{array}{ll}\text { re } & 0.162 \\
{[0.080,0.301]}\end{array}$ & $\begin{array}{r}0.216 \\
{[0.100,0.408]}\end{array}$ & $\begin{array}{r}0.501 \\
{[0.233,0.768]} \\
\end{array}$ & $\begin{array}{r}0.215 \\
{[0.136,0.324} \\
\end{array}$ \\
\hline$\overline{\mathrm{N}}$ & 342 & & & \\
\hline
\end{tabular}


Level of Obstacle of PRACTICES OF COMPETITORS IN THE INFORMAL SECTOR to the functioning of the establishment

\begin{tabular}{|c|c|c|c|c|}
\hline & $\begin{array}{c}\text { Small }<= \\
19\end{array}$ & $\begin{array}{c}\text { Medium } \\
>=20 \text { and }<=99\end{array}$ & $\begin{array}{c}\text { Large }>= \\
100\end{array}$ & Total \\
\hline \multirow[t]{2}{*}{ None } & 0.0627 & 0.222 & 0.0895 & 0.126 \\
\hline & {$[0.013,0.256]$} & {$[0.087,0.460]$} & {$[0.032,0.225]$} & {$[0.059,0.251$} \\
\hline \multirow[t]{2}{*}{ Major or very sever } & 0.544 & 0.46 & 0.4 & 0.498 \\
\hline & {$[0.363,0.714]$} & {$[0.275,0.657]$} & {$[0.184,0.662]$} & {$[0.375,0.621$} \\
\hline $\mathrm{N}$ & 352 & & & \\
\hline
\end{tabular}

Level of Obstacle of ACCESS TO LAND to the functioning of the establishment

\begin{tabular}{|c|c|c|c|c|}
\hline & $\begin{array}{c}\text { Small }<= \\
19 \\
\end{array}$ & $\begin{array}{c}\text { Medium } \\
>=20 \text { and }<=99\end{array}$ & $\begin{array}{c}\text { Large }>= \\
100\end{array}$ & Total \\
\hline \multirow[t]{2}{*}{ None } & 0.432 & 0.54 & 0.2 & 0.449 \\
\hline & {$[0.267,0.614]$} & {$[0.345,0.724]$} & {$[0.096,0.371]$} & {$[0.329,0.576]$} \\
\hline \multirow[t]{2}{*}{ Major or very sever } & 0.169 & 0.158 & 0.078 & 0.156 \\
\hline & {$[0.071,0.351]$} & {$[0.064,0.342]$} & {$[0.030,0.186]$} & {$[0.086,0.266]$} \\
\hline $\mathrm{N}$ & 351 & & & \\
\hline
\end{tabular}

Level of Obstacle of FUNCTIONING OF THE COURTS to the functioning of the establishment

\begin{tabular}{|c|c|c|c|c|}
\hline & $\begin{array}{c}\text { Small }<= \\
19\end{array}$ & $\begin{array}{c}\text { Medium } \\
>=20 \text { and }<=99\end{array}$ & $\begin{array}{c}\text { Large }>= \\
100\end{array}$ & Total \\
\hline \multirow[t]{2}{*}{ None } & 0.265 & 0.291 & 0.126 & 0.262 \\
\hline & {$[0.130,0.466]$} & {$[0.138,0.511]$} & {$[0.053,0.271]$} & {$[0.162,0.395]$} \\
\hline \multirow[t]{2}{*}{ Major or very sever } & 0.329 & 0.349 & 0.477 & 0.351 \\
\hline & {$[0.179,0.523]$} & {$[0.188,0.553]$} & {$[0.198,0.770]$} & {$[0.240,0.482]$} \\
\hline $\mathrm{N}$ & 337 & & & \\
\hline
\end{tabular}

Level of Obstacle of CRIME, THEFT AND DISORDER to the functioning of the establishment

\begin{tabular}{|c|c|c|c|c|}
\hline & $\begin{array}{c}\text { Small }<= \\
19 \\
\end{array}$ & $\begin{array}{c}\text { Medium } \\
>=20 \text { and }<=99\end{array}$ & $\begin{array}{c}\text { Large }>= \\
100 \\
\end{array}$ & Total \\
\hline None & $\begin{array}{r}0.191 \\
{[0.084,0.378]} \\
\end{array}$ & $\begin{array}{r}0.103 \\
{[0.033,0.281]} \\
\end{array}$ & $\begin{array}{r}0.0565 \\
{[0.024,0.129]} \\
\end{array}$ & $\begin{array}{r}0.145 \\
{[0.076,0.258]}\end{array}$ \\
\hline Major or very sever & 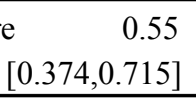 & $\begin{array}{r}0.366 \\
{[0.204,0.566]} \\
\end{array}$ & $\begin{array}{r}0.264 \\
{[0.106,0.520]} \\
\end{array}$ & $\begin{array}{r}0.452 \\
{[0.334,0.576]} \\
\end{array}$ \\
\hline $\mathrm{N}$ & 360 & & & \\
\hline
\end{tabular}


Level of Obstacle of TAX RATES to the functioning of the establishment

\begin{tabular}{lrrrr}
\hline \hline & $\begin{array}{c}\text { Small }<= \\
\mathbf{1 9}\end{array}$ & $\begin{array}{c}\text { Medium } \\
\text { and }<=\mathbf{9 9}\end{array}$ & $\begin{array}{c}\text { Large }>= \\
\mathbf{1 0 0}\end{array}$ & Total \\
\hline \hline None & 0.112 & 0.402 & 0.501 & 0.261 \\
& {$[0.043,0.259]$} & {$[0.227,0.607]$} & {$[0.234,0.767]$} & {$[0.167,0.385]$} \\
\hline Major or very severe $\quad 0.089$ & 0.17 & 0.103 & 0.122 \\
& {$[0.030,0.235]$} & {$[0.072,0.351]$} & {$[0.042,0.229]$} & {$[0.066,0.214]$} \\
\hline $\mathrm{N}$ & 361 & & & \\
\hline 95\% confidence intervals in brackets
\end{tabular}

Level of Obstacle of TAX ADMINISTRATION to the functioning of the establishment

\begin{tabular}{lrrrr}
\hline \hline & $\begin{array}{c}\text { Small }<= \\
\mathbf{1 9}\end{array}$ & $\begin{array}{c}\text { Medium } \\
\mathbf{2}=\mathbf{2 0} \text { and }<=\mathbf{9 9}\end{array}$ & $\begin{array}{c}\text { Large }>= \\
\mathbf{1 0 0}\end{array}$ & Total \\
\hline \hline None & 0.121 & 0.395 & 0.447 & 0.258 \\
& {$[0.050,0.265]$} & {$[0.219,0.602]$} & {$[0.182,0.746]$} & {$[0.163,0.382]$} \\
\hline Major or very severe & 0.0339 & 0.164 & 0.0877 & 0.0889 \\
& {$[0.012,0.092]$} & {$[0.067,0.347]$} & {$[0.033,0.215]$} & {$[0.045,0.166]$} \\
\hline $\mathrm{N}$ & 359 & & & \\
\hline 95\% confidence intervals in brackets & & &
\end{tabular}

Level of Obstacle of BUSINESS LICENSING AND PERMITS

to the functioning of the establishment

\begin{tabular}{lrrrr}
\hline \hline & $\begin{array}{c}\text { Small }<= \\
\mathbf{1 9}\end{array}$ & $\begin{array}{c}\text { Medium } \\
\mathbf{>}=\mathbf{2 0} \text { and }<=\mathbf{9 9}\end{array}$ & $\begin{array}{c}\text { Large }>= \\
\mathbf{1 0 0}\end{array}$ & Total \\
\hline \hline None & 0.155 & 0.287 & 0.374 & 0.227 \\
& {$[0.074,0.295]$} & {$[0.136,0.508]$} & {$[0.119,0.725]$} & {$[0.139,0.347]$} \\
\hline Major or very severe & 0.147 & 0.113 & 0.0997 & 0.13 \\
& {$[0.057,0.332]$} & {$[0.054,0.221]$} & {$[0.040,0.230]$} & {$[0.070,0.227]$} \\
\hline $\mathrm{N}$ & 361 & & & \\
\hline 95\% confidence intervals in brackets
\end{tabular}

Level of Obstacle of POLITICAL INSTABILITY to the functioning of the establishment

\begin{tabular}{|c|c|c|c|c|}
\hline & $\begin{array}{c}\text { Small }<= \\
19\end{array}$ & $\begin{array}{c}\text { Medium } \\
>=20 \text { and }<=99\end{array}$ & $\begin{array}{c}\text { Large }>= \\
100\end{array}$ & Total \\
\hline None & $\begin{array}{r}0.102 \\
{[0.037,0.253]}\end{array}$ & $\begin{array}{r}0.132 \\
{[0.044,0.334]}\end{array}$ & $\begin{array}{c}0.0304 \\
{[0.010,0.085]}\end{array}$ & $\begin{array}{r}0.107 \\
{[0.052,0.207]}\end{array}$ \\
\hline Major or very sever & $\begin{array}{l}\text { e } \quad 0.457 \\
{[0.291,0.632]}\end{array}$ & $\begin{array}{r}0.545 \\
{[0.348,0.729]}\end{array}$ & $\begin{array}{c}0.537 \\
{[0.248,0.803]}\end{array}$ & $\begin{array}{r}0.498 \\
{[0.377,0.620]}\end{array}$ \\
\hline $\mathrm{N}$ & 360 & & & \\
\hline
\end{tabular}


Level of Obstacle of CORRUPTION to the functioning of the establishment

\begin{tabular}{lrrrr}
\hline \hline & $\begin{array}{c}\text { Small }<= \\
\mathbf{1 9}\end{array}$ & $\begin{array}{c}\text { Medium } \\
>=\mathbf{2 0} \text { and }<=\mathbf{9 9}\end{array}$ & $\begin{array}{c}\text { Large }>= \\
\mathbf{1 0 0}\end{array}$ & Total \\
\hline \hline None & 0.166 & 0.109 & 0.142 & 0.142 \\
& {$[0.069,0.349]$} & {$[0.032,0.313]$} & {$[0.047,0.360]$} & {$[0.074,0.253]$} \\
\hline Major or very severe & 0.59 & 0.579 & 0.688 & 0.595 \\
& {$[0.407,0.751]$} & {$[0.375,0.759]$} & {$[0.450,0.856]$} & {$[0.469,0.711]$} \\
\hline $\mathrm{N}$ & 358 & & & \\
\hline 95\% confidence intervals in brackets
\end{tabular}

Level of Obstacle of ACCESS TO FINANCING to the functioning of the establishment

\begin{tabular}{|c|c|c|c|c|}
\hline & $\begin{array}{c}\text { Small }<= \\
19\end{array}$ & $\begin{array}{c}\text { Medium } \\
>=20 \text { and }<=99\end{array}$ & $\begin{array}{c}\text { Large }>= \\
100\end{array}$ & Total \\
\hline None & $\begin{array}{r}0.225 \\
{[0.110,0.408]} \\
\end{array}$ & $\begin{array}{r}0.315 \\
{[0.163,0.521]} \\
\end{array}$ & $\begin{array}{c}0.298 \\
{[0.130,0.546]} \\
\end{array}$ & $\begin{array}{r}0.267 \\
{[0.174,0.388]} \\
\end{array}$ \\
\hline Major or very severe & $\begin{array}{l}\text { e } \begin{array}{r}0.289 \\
{[0.151,0.481]}\end{array} \\
\end{array}$ & $\begin{array}{r}0.279 \\
{[0.131,0.497]}\end{array}$ & $\begin{array}{c}0.315 \\
{[0.075,0.723]}\end{array}$ & $\begin{array}{r}0.287 \\
{[0.183,0.420]} \\
\end{array}$ \\
\hline $\mathrm{N}$ & 351 & & & \\
\hline
\end{tabular}

Level of Obstacle of LABOR REGULATIONS to the functioning of the establishment

\begin{tabular}{lcccr}
\hline \hline & $\begin{array}{c}\text { Small }<= \\
\mathbf{1 9}\end{array}$ & $\begin{array}{c}\text { Medium } \\
\text { >=20 and }<=\mathbf{9 9}\end{array}$ & $\begin{array}{c}\text { Large }>= \\
\mathbf{1 0 0}\end{array}$ & Total \\
\hline \hline None & 0.111 & 0.0931 & 0.0368 & 0.0969 \\
& {$[0.042,0.263]$} & {$[0.042,0.194]$} & {$[0.014,0.091]$} & {$[0.051,0.177]$} \\
\hline Major or very severe & 0.343 & 0.293 & 0.289 & 0.319 \\
& {$[0.197,0.527]$} & $0.153,0.488]$ & {$[0.131,0.522]$} & {$[0.218,0.440]$} \\
\hline N & & & \\
\hline 95\% confidence intervals in brackets
\end{tabular}

Level of Obstacle of INADEQUATELY EDUCATED WORKFORCE to the functioning of the establishment

\begin{tabular}{|c|c|c|c|c|}
\hline & $\begin{array}{c}\text { Small }<= \\
19\end{array}$ & $\begin{array}{c}\text { Medium } \\
>=20 \text { and }<=99\end{array}$ & $\begin{array}{c}\text { Large }>= \\
100\end{array}$ & Total \\
\hline None & $\begin{array}{r}0.0808 \\
{[0.023,0.249]}\end{array}$ & $\begin{array}{r}0.0962 \\
{[0.024,0.313]} \\
\end{array}$ & $\begin{array}{c}0.0209 \\
{[0.006,0.067]}\end{array}$ & $\begin{array}{r}0.081 \\
{[0.033,0.186]}\end{array}$ \\
\hline Major or very sever & $\begin{array}{l}\text { e } \\
{[0.252,0.590]}\end{array}$ & $\begin{array}{r}0.341 \\
{[0.188,0.536]}\end{array}$ & $\begin{array}{c}0.239 \\
{[0.116,0.430]}\end{array}$ & $\begin{array}{r}0.367 \\
{[0.260,0.490]}\end{array}$ \\
\hline $\mathrm{N}$ & 358 & & & \\
\hline
\end{tabular}


APPENDIX II

Model Selection

\begin{tabular}{|c|c|c|c|c|}
\hline \multirow{3}{*}{ REGRESSORS } & \multicolumn{4}{|c|}{ Electricity } \\
\hline & \multicolumn{2}{|c|}{ OProbit } & \multicolumn{2}{|c|}{ IV OProbit } \\
\hline & Coef. & $P$ value & Coef. & $P$ value \\
\hline Size $=$ Medium $>=20$ and $<=99$ & 0.479 & 0.126 & 1.132 & 0.001 \\
\hline Size $=$ Large $>=100$ & 0.523 & 0.219 & 1.827 & 0.012 \\
\hline Type $=$ Manufacturing & 0.850 & 0.04 & 1.000 & 0.006 \\
\hline City $=$ Santa Cruz & 0.516 & 0.103 & 0.678 & 0.006 \\
\hline Industry $=$ Construction Section F & 1.794 & 0.022 & 1.827 & 0.006 \\
\hline Industry $=$ Services of Motor Vehicles & 0.570 & 0.342 & 1.139 & 0.031 \\
\hline Industry $=$ Wholesale & 1.094 & 0.008 & 1.021 & 0.005 \\
\hline Industry $=$ Retail & 0.697 & 0.092 & 0.796 & 0.086 \\
\hline Industry $=$ Transport Section I & 0.965 & 0.01 & 1.134 & 0.005 \\
\hline Years Experience Top Manager & 0.023 & 0.062 & 0.024 & 0.041 \\
\hline Internationally recognized quality certification $=\mathrm{No}$ & 0.707 & 0.045 & 0.882 & 0.005 \\
\hline Growth & 2.457 & 0.058 & 2.210 & 0.077 \\
\hline /cut 11 & 0.271 & 0.688 & 0.143 & 0.812 \\
\hline$/$ cut 12 & 0.514 & 0.432 & 0.850 & 0.130 \\
\hline /cut 13 & 0.858 & 0.181 & 1.168 & 0.034 \\
\hline /cut 14 & 1.220 & 0.054 & 1.508 & 0.005 \\
\hline Athrho & & & 0.698 & 0.036 \\
\hline Underidentification test & $\begin{array}{l}\text { (Kleibergen Paal } \\
\text { Chi sq(4) P val }\end{array}$ & rk LM statistic): & & $\begin{array}{c}3941.662 \\
0.000\end{array}$ \\
\hline Overidentification test & $\begin{array}{l}\text { Hansen J statistic } \\
\text { Chi sq(3) P val = }\end{array}$ & & & $\begin{array}{l}3.903 \\
0.272\end{array}$ \\
\hline
\end{tabular}

\begin{tabular}{|c|c|c|c|c|}
\hline \multirow{3}{*}{ REGRESSORS } & \multicolumn{4}{|c|}{ Telecommunications } \\
\hline & \multicolumn{2}{|c|}{ OProbit } & \multicolumn{2}{|c|}{ IV OProbit } \\
\hline & Coef. & P value & Coef. & P value \\
\hline \multicolumn{5}{|l|}{ Size $=$ Small $>=5$ and $<=19$} \\
\hline Size $=$ Medium $>=20$ and $<=99$ & 0.357 & 0.298 & 1.052 & 0.001 \\
\hline Size $=$ Large $>=100$ & 0.136 & 0.721 & 1.529 & 0.006 \\
\hline Type $=$ Manufacturing & 0.715 & 0.025 & 0.736 & 0.011 \\
\hline Type $=$ Retail & 1.409 & 0.000 & 1.033 & 0.012 \\
\hline City $=$ La Paz & 0.580 & 0.203 & 0.686 & 0.080 \\
\hline City $=$ Santa Cruz & 0.920 & 0.062 & 1.166 & 0.003 \\
\hline Industry $=$ Wholesale & 1.283 & 0.001 & 0.886 & 0.019 \\
\hline Industry $=$ Retail & 1.798 & 0.007 & 1.379 & 0.061 \\
\hline Internationally & 1.033 & 0.038 & 0.863 & 0.076 \\
\hline Internationally recognized quality certification $=\mathrm{No}$ & 0.983 & 0.015 & 1.064 & 0.008 \\
\hline Growth & 3.056 & 0.010 & 2.591 & 0.020 \\
\hline /cut 11 & 0.260 & 0.693 & 0.079 & 0.896 \\
\hline /cut_1_2 & 0.200 & 0.756 & 0.497 & 0.397 \\
\hline /cut 13 & 0.894 & 0.168 & 1.121 & 0.063 \\
\hline /cut 14 & 1.518 & 0.015 & 1.688 & 0.004 \\
\hline Athrho & & & 0.736 & 0.002 \\
\hline Underidentification test & $\begin{array}{l}\text { (Kleiberger } \\
\text { Chi sq(4) P }\end{array}$ & rk LM statistic): & & $\begin{array}{c}28.339 \\
0.000\end{array}$ \\
\hline Overidentification test & $\begin{array}{l}\text { Hansen J st } \\
\text { Chi sq(3) P }\end{array}$ & & & $\begin{array}{l}3.965 \\
0.265\end{array}$ \\
\hline
\end{tabular}




\section{Model Selection (continued)}

\begin{tabular}{|c|c|c|c|c|}
\hline \multirow{3}{*}{ REGRESSOS } & \multicolumn{4}{|c|}{ Transportation } \\
\hline & \multicolumn{2}{|c|}{ OProbit } & \multicolumn{2}{|c|}{ IV OProbit } \\
\hline & Coef. & P value & Coef. & P value \\
\hline \multicolumn{5}{|l|}{ Size $=$ Small $>=5$ and $<=19$} \\
\hline Size $=$ Medium $>=20$ and $<=99$ & 0.678 & 0.053 & 1.327 & 0.001 \\
\hline Size $=$ Large $>=100$ & 0.991 & 0.002 & 2.173 & 0.000 \\
\hline City $=$ Santa Cruz & 0.558 & 0.085 & 0.752 & 0.009 \\
\hline Industry $=$ Garments & 0.351 & 0.244 & 0.569 & 0.053 \\
\hline Industry $=$ Services of Motor Vehicles & 1.333 & 0.065 & 1.655 & 0.009 \\
\hline Legal Status $=$ Sole (propietorship) & 0.524 & 0.160 & 0.701 & 0.060 \\
\hline Internationally recognized quality certification $=$ Yes & 1.467 & 0.003 & 1.313 & 0.007 \\
\hline Internationally recognized quality certification $=$ No & 1.355 & 0.008 & 1.421 & 0.002 \\
\hline /cut 11 & 0.682 & 0.212 & 1.101 & 0.032 \\
\hline /cut_1_2 & 1.371 & 0.010 & 1.727 & 0.000 \\
\hline /cut 13 & 2.154 & 0.000 & 2.454 & 0.000 \\
\hline /cut_1_4 & 2.588 & 0.000 & 2.865 & 0.000 \\
\hline Athrho & & & 0.600 & 0.048 \\
\hline Underidentification test & $\begin{array}{l}\text { (Kleibergen } \\
\text { Chi sq(5) P }\end{array}$ & rk LM stat & & $\begin{array}{c}4082.000 \\
0.000\end{array}$ \\
\hline Overidentification test & $\begin{array}{l}\text { Hansen J st } \\
\text { Chi sq(4) P }\end{array}$ & & & $\begin{array}{l}8.560 \\
0.073\end{array}$ \\
\hline
\end{tabular}

Underidentification Test and Overidentification Test calculated on a IV linear model.

\begin{tabular}{|c|c|c|c|c|}
\hline \multirow{3}{*}{ REGRESSOS } & \multicolumn{4}{|c|}{ Customs and Trade Regulation } \\
\hline & \multicolumn{2}{|c|}{ OProbit } & \multicolumn{2}{|c|}{ IV OProbit } \\
\hline & Coef. & P value & Coef. & $P$ value \\
\hline \multicolumn{5}{|l|}{ Size $=$ Small $>=5$ and $<=19$} \\
\hline Size $=$ Medium $>=20$ and $<=99$ & 0.141 & 0.627 & 0.269 & 0.418 \\
\hline Size $=$ Large $>=100$ & 0.502 & 0.182 & 0.198 & 0.732 \\
\hline Type $=$ Manufacturing & 0.712 & 0.022 & 0.747 & 0.016 \\
\hline Type $=$ Retail & 0.777 & 0.022 & 0.800 & 0.014 \\
\hline Industry $=$ Construction Section F & 2.277 & 0.021 & 2.291 & 0.018 \\
\hline Industry $=$ Wholesale & 1.330 & 0.001 & 1.312 & 0.001 \\
\hline Industry $=$ Transport Section I & 0.998 & 0.016 & 1.011 & 0.011 \\
\hline Internationally & 2.561 & 0.000 & 2.572 & 0.000 \\
\hline Internationally recognized quality certification $=$ No & 1.166 & 0.016 & 1.117 & 0.025 \\
\hline Growth & 2.141 & 0.061 & 2.134 & 0.065 \\
\hline$/$ cut 111 & 1.925 & 0.000 & 1.837 & 0.001 \\
\hline /cut_1_2 & 2.375 & 0.000 & 2.286 & 0.000 \\
\hline /cut 13 & 3.473 & 0.000 & 3.374 & 0.000 \\
\hline /cut_1_4 & 4.666 & 0.000 & 4.554 & 0.000 \\
\hline Athrho & & & 0.148 & 0.389 \\
\hline Underidentification test & $\begin{array}{l}\text { (Kleiberger } \\
\text { Chi sq(7) P }\end{array}$ & rk LM sta & & $\begin{array}{c}31.379 \\
0.000 \\
\end{array}$ \\
\hline Overidentification test & $\begin{array}{l}\text { Hansen J st } \\
\text { Chi sq(6) P }\end{array}$ & & & $\begin{array}{l}4.144 \\
0.657\end{array}$ \\
\hline
\end{tabular}

CInternational Monetary Fund. Not for Redistribution 
Model Selection (continued)

\begin{tabular}{|c|c|c|c|c|}
\hline \multirow{3}{*}{ REGRESSORS } & \multicolumn{4}{|c|}{ Practices of Competitors in the Informal Sector } \\
\hline & \multicolumn{2}{|c|}{ OProbit } & \multicolumn{2}{|c|}{ IV OProbit } \\
\hline & Coef. & P value & Coef. & P value \\
\hline \multicolumn{5}{|l|}{ Size $=$ Small $>=5$ and $<=19$} \\
\hline Size $=$ Medium $>=20$ and $<=99$ & 0.319 & 0.248 & 0.289 & 0.450 \\
\hline Size $=$ Large $>=100$ & 0.324 & 0.336 & 1.434 & 0.012 \\
\hline Type $=$ Manufacturing & 0.828 & 0.005 & 0.810 & 0.004 \\
\hline City $=\mathrm{La} \mathrm{Paz}$ & 1.255 & 0.001 & 1.276 & 0.000 \\
\hline City $=$ Santa Cruz & 0.964 & 0.006 & 1.154 & 0.001 \\
\hline Industry $=$ Garments & 1.979 & 0.005 & 1.597 & 0.013 \\
\hline Industry $=$ Chemicals & 2.004 & 0.000 & 2.144 & 0.000 \\
\hline Industry $=$ Services of Motor Vehicles & 1.461 & 0.097 & 1.756 & 0.024 \\
\hline Legal Status $=$ Privately held, limited liability company & 0.616 & 0.098 & 0.876 & 0.005 \\
\hline Percentage held by largest owner ( $2549 \%)$ & 1.365 & 0.000 & 1.297 & 0.000 \\
\hline Percentage held by largest owner (50 $74 \%$ ) & 0.675 & 0.020 & 0.620 & 0.017 \\
\hline Years Experience Top Manager & 0.022 & 0.041 & 0.019 & 0.071 \\
\hline Internationally recognized quality certification $=\mathrm{No}$ & 0.301 & 0.286 & 0.530 & 0.074 \\
\hline /cut 111 & 2.951 & 0.000 & 2.398 & 0.000 \\
\hline /cut 12 & 2.541 & 0.000 & 2.009 & 0.001 \\
\hline /cut 13 & 1.336 & 0.002 & 0.897 & 0.090 \\
\hline /cut 14 & 0.482 & 0.278 & 0.089 & 0.859 \\
\hline Athrho & & & 0.533 & 0.052 \\
\hline Underidentification test & $\begin{array}{l}\text { (Kleibergen } \\
\text { Chi sq(5) P }\end{array}$ & rk LM statistic): & & $\begin{array}{c}3277.000 \\
0.000\end{array}$ \\
\hline Overidentification test & $\begin{array}{l}\text { Hansen J st } \\
\text { Chi sq(4) P }\end{array}$ & & & $\begin{array}{l}4.035 \\
0.401\end{array}$ \\
\hline
\end{tabular}

Underidentification Test and Overidentification Test calculated on a IV linear model.

\begin{tabular}{|c|c|c|c|c|}
\hline \multirow{3}{*}{ REGRESSOS } & \multicolumn{4}{|c|}{ Access to Land } \\
\hline & \multicolumn{2}{|c|}{ OProbit } & \multicolumn{2}{|c|}{ IV OProbit } \\
\hline & Coef. & P value & Coef. & P value \\
\hline \multicolumn{5}{|l|}{ Size $=$ Small $>=5$ and $<=19$} \\
\hline Size $=$ Medium $>=20$ and $<=99$ & 0.179 & 0.527 & 0.236 & 0.494 \\
\hline Size $=$ Large $>=100$ & 0.262 & 0.377 & 0.139 & 0.806 \\
\hline City $=$ Santa Cruz & 0.603 & 0.021 & 0.584 & 0.031 \\
\hline Industry $=$ Foods & 0.997 & 0.027 & 1.027 & 0.030 \\
\hline Industry $=$ Hotel and restaurants: section $\mathrm{H}$ & 0.574 & 0.018 & 0.575 & 0.019 \\
\hline Industry $=$ Transport Section I & 0.851 & 0.005 & 0.859 & 0.006 \\
\hline Percentage held by largest owner (50 74\%) & 0.675 & 0.047 & 0.679 & 0.045 \\
\hline Internationally & 1.986 & 0.000 & 2.016 & 0.000 \\
\hline Internationally recognized quality certification $=$ No & 1.702 & 0.000 & 1.704 & 0.000 \\
\hline /cut_1_1 & 1.653 & 0.001 & 1.636 & 0.001 \\
\hline /cut_1_2 & 2.150 & 0.000 & 2.133 & 0.000 \\
\hline /cut_1_3 & 2.990 & 0.000 & 2.972 & 0.000 \\
\hline /cut_1_4 & 4.285 & 0.000 & 4.268 & 0.000 \\
\hline Athrho & & & 0.054 & 0.798 \\
\hline Underidentification test & \multicolumn{3}{|c|}{$\begin{array}{l}\text { (Kleibergen Paap rk LM statistic): } \\
\text { Chi sq(5) P val = }\end{array}$} & $\begin{array}{c}4195.000 \\
0.000\end{array}$ \\
\hline Overidentification test & \multicolumn{3}{|c|}{ Hansen J statistic: } & $\begin{array}{l}1.108 \\
0.893\end{array}$ \\
\hline
\end{tabular}

Underidentification Test and Overidentification Test calculated on a IV linear model. 


\section{Model Selection (continued)}

\begin{tabular}{|c|c|c|c|c|}
\hline \multirow{3}{*}{ REGRESSORS } & \multicolumn{4}{|c|}{ Courts } \\
\hline & \multicolumn{2}{|c|}{ OProbit } & \multicolumn{2}{|c|}{ IV OProbit } \\
\hline & Coef. & P value & Coef. & P value \\
\hline \multicolumn{5}{|l|}{ Size $=$ Small $>=5$ and $<=19$} \\
\hline Size $=$ Medium $>=20$ and $<=99$ & 0.427 & 0.209 & 0.708 & 0.120 \\
\hline Size $=$ Large $>=100$ & 0.754 & 0.052 & 1.429 & 0.036 \\
\hline Type $=$ Manufacturing & 0.80 & 0.007 & 0.873 & 0.003 \\
\hline Type $=$ Retail & 0.94 & 0.002 & 0.972 & 0.002 \\
\hline Industry $=$ Textiles & 1.78 & 0.007 & 1.726 & 0.004 \\
\hline Legal Status = Publicly listed company & 2.895 & 0.000 & 2.895 & 0.000 \\
\hline Legal Status $=$ Privately held, limited liability compa & 2.434 & 0.002 & 2.377 & 0.003 \\
\hline Legal Status = Sole (propietorship) & 2.893 & 0.000 & 3.051 & 0.000 \\
\hline Legal Status $=$ Partnership & 2.393 & 0.002 & 2.454 & 0.001 \\
\hline /cut_1_1 & 1.380 & 0.069 & 1.611 & 0.045 \\
\hline /cut 12 & 1.884 & 0.015 & 2.103 & 0.010 \\
\hline /cut_1_3 & 2.584 & 0.001 & 2.785 & 0.001 \\
\hline /cut_1_4 & 3.702 & 0.000 & 3.877 & 0.000 \\
\hline Athrho & & & 0.301 & 0.197 \\
\hline Underidentification test & $\begin{array}{l}\text { (Kleiberge } \\
\text { Chi sq(5) }\end{array}$ & rk LM sta & & $\begin{array}{c}2423.000 \\
0.000 \\
\end{array}$ \\
\hline Overidentification test & $\begin{array}{l}\text { Hansen J s } \\
\text { Chi sq(4) }\end{array}$ & & & $\begin{array}{l}4.144 \\
0.387\end{array}$ \\
\hline
\end{tabular}

\begin{tabular}{|c|c|c|c|c|}
\hline \multirow{3}{*}{ REGRESSORS } & \multicolumn{4}{|c|}{ Crime Theft and Disorder } \\
\hline & \multicolumn{2}{|c|}{ OProbit } & \multicolumn{2}{|c|}{ IV OProbit } \\
\hline & Coef. & P value & Coef. & P value \\
\hline \multicolumn{5}{|l|}{ Size $=$ Small $>=5$ and $<=19$} \\
\hline Size $=$ Medium $>=20$ and $<=99$ & 0.479 & 0.086 & 0.803 & 0.040 \\
\hline Size $=$ Large $>=100$ & 0.259 & 0.394 & 1.069 & 0.186 \\
\hline Industry $=$ Textiles & 1.878 & 0.006 & 1.940 & 0.012 \\
\hline Industry $=$ Retail & 0.683 & 0.012 & 0.637 & 0.013 \\
\hline Industry $=$ Hotel and restaurants: section $\mathrm{H}$ & 0.704 & 0.056 & 0.635 & 0.077 \\
\hline Industry $=$ Transport Section I & 0.988 & 0.009 & 0.983 & 0.001 \\
\hline /cut 11 & 1.244 & 0.000 & 1.425 & 0.000 \\
\hline /cut 12 & 0.597 & 0.039 & 0.801 & 0.013 \\
\hline /cut 13 & 0.051 & 0.854 & 0.172 & 0.607 \\
\hline /cut 14 & 0.988 & 0.001 & 0.734 & 0.068 \\
\hline Athrho & & & 0.382 & 0.329 \\
\hline Underidentification test & $\begin{array}{l}\text { (Kleiberger } \\
\text { Chi sq(5) P }\end{array}$ & rk LM sta & & $\begin{array}{c}3926.000 \\
0.000\end{array}$ \\
\hline Overidentification test & $\begin{array}{l}\text { Hansen J st } \\
\text { Chi sq(4) P }\end{array}$ & & & $\begin{array}{l}3.067 \\
0.547\end{array}$ \\
\hline
\end{tabular}

Underidentification Test and Overidentification Test calculated on a IV linear model. 


\section{Model Selection (continued)}

\begin{tabular}{|c|c|c|c|c|}
\hline \multirow{3}{*}{ REGRESSORS } & \multicolumn{4}{|c|}{ Tax Rates } \\
\hline & \multicolumn{2}{|c|}{ OProbit } & \multicolumn{2}{|c|}{ IV OProbit } \\
\hline & Coef. & P value & Coef. & P value \\
\hline \multicolumn{5}{|l|}{ Size $=$ Small $>=5$ and $<=19$} \\
\hline Size $=$ Medium $>=20$ and $<=99$ & 0.60 & 0.034 & 0.609 & 0.120 \\
\hline Size $=$ Large $>=100$ & 0.83 & 0.011 & 0.852 & 0.100 \\
\hline Type $=$ Manufacturing & 0.61 & 0.010 & 0.609 & 0.009 \\
\hline Industry = Other Manufacturing & 0.858 & 0.000 & 0.855 & 0.000 \\
\hline Industry $=$ Garments & 0.906 & 0.058 & 0.908 & 0.067 \\
\hline Industry $=$ Chemicals & 0.90 & 0.001 & 0.906 & 0.004 \\
\hline Industry $=$ Hotel and restaurants: section $\mathrm{H}$ & 1.155 & 0.001 & 1.155 & 0.001 \\
\hline Legal Status = Privately held, limited liability compa & 0.818 & 0.034 & 0.823 & 0.030 \\
\hline Percentage held by largest owner $(024 \%)$ & 2.31 & 0.000 & 2.301 & 0.000 \\
\hline Percentage held by largest owner (50 74\%) & 0.594 & 0.022 & 0.594 & 0.022 \\
\hline Internationally recognized quality certification $=$ Yes & 0.545 & 0.017 & 0.548 & 0.035 \\
\hline /cut_1_1 & 0.79 & 0.001 & 0.794 & 0.002 \\
\hline /cut 12 & 0.12 & 0.562 & 0.124 & 0.590 \\
\hline /cut 13 & 1.534 & 0.000 & 1.531 & 0.000 \\
\hline /cut 14 & 2.090 & 0.000 & 2.087 & 0.000 \\
\hline Athrho & & & 0.006 & 0.970 \\
\hline Underidentification test & \multicolumn{2}{|c|}{$\begin{array}{l}\text { (Kleibergen Paap rk LM statistic): } \\
\text { Chi sq(6) P val = }\end{array}$} & & $\begin{array}{c}3350.000 \\
0.001 \\
\end{array}$ \\
\hline Overidentification test & \multicolumn{2}{|c|}{$\begin{array}{l}\text { Hansen J statistic: } \\
\text { Chi sq(5) P val = }\end{array}$} & & $\begin{array}{l}1.787 \\
0.878\end{array}$ \\
\hline
\end{tabular}

Underidentification Test and Overidentification Test calculated on a IV linear model

\begin{tabular}{|c|c|c|c|c|}
\hline \multirow{3}{*}{ REGRESSORS } & \multicolumn{4}{|c|}{ Tax Administration } \\
\hline & \multicolumn{2}{|c|}{ OProbit } & \multicolumn{2}{|c|}{ IV OProbit } \\
\hline & Coef. & P value & Coef. & P value \\
\hline \multicolumn{5}{|l|}{ Size $=$ Small $>=5$ and $<=19$} \\
\hline Size $=$ Medium $>=20$ and $<=99$ & 0.722 & 0.008 & 0.763 & 0.052 \\
\hline Size $=$ Large $>=100$ & 0.616 & 0.074 & 0.710 & 0.203 \\
\hline Industry $=$ Other Manufacturing & 0.619 & 0.019 & 0.606 & 0.025 \\
\hline Industry $=$ Textiles & 1.760 & 0.003 & 1.765 & 0.004 \\
\hline Industry $=$ Hotel and restaurants: section $\mathrm{H}$ & 1.162 & 0.000 & 1.160 & 0.000 \\
\hline Legal Status = Privately held, limited liability company & ny $\quad 0.835$ & 0.013 & 0.864 & 0.015 \\
\hline Percentage held by largest owner $(024 \%)$ & 1.679 & 0.004 & 1.604 & 0.021 \\
\hline Percentage held by largest owner (50 74\%) & 0.670 & 0.020 & 0.672 & 0.019 \\
\hline Principal Owner Gender= Female / Are any of the pri & 0.479 & 0.060 & 0.483 & 0.061 \\
\hline Growth & 1.925 & 0.092 & 1.903 & 0.098 \\
\hline /cut_1_1 & 0.826 & 0.000 & 0.850 & 0.001 \\
\hline /cut 12 & 0.196 & 0.451 & 0.219 & 0.472 \\
\hline /cut 13 & 1.774 & 0.000 & 1.750 & 0.000 \\
\hline /cut 14 & 2.287 & 0.000 & 2.260 & 0.000 \\
\hline Athrho & & & 0.039 & 0.842 \\
\hline Underidentification test & \multicolumn{2}{|c|}{$\begin{array}{l}\text { (Kleibergen Paap rk LM statistic): } \\
\text { Chi sq(6) P val = }\end{array}$} & & $\begin{array}{c}23.417 \\
0.001 \\
\end{array}$ \\
\hline Overidentification test & \multicolumn{2}{|c|}{$\begin{array}{l}\text { Hansen J statistic: } \\
\text { Chi sq(5) P val = }\end{array}$} & & $\begin{array}{l}2.961 \\
0.706\end{array}$ \\
\hline
\end{tabular}

Underidentification Test and Overidentification Test calculated on a IV linear model. 


\section{Model Selection (continued)}

\begin{tabular}{|c|c|c|c|c|}
\hline \multirow{3}{*}{ REGRESSORS } & \multicolumn{4}{|c|}{ Business Licensing and Permits } \\
\hline & \multicolumn{2}{|c|}{ OProbit } & \multicolumn{2}{|c|}{ IV OProbit } \\
\hline & Coef. & P value & Coef. & Pvalue \\
\hline \multicolumn{5}{|l|}{ Size $=$ Small $>=5$ and $<=19$} \\
\hline Size $=$ Medium $>=20$ and $<=99$ & 0.792 & 0.002 & 1.125 & 0.000 \\
\hline Size $=$ Large $>=100$ & 1.358 & 0.002 & 2.245 & 0.000 \\
\hline Type $=$ Manufacturing & 0.591 & 0.097 & 0.720 & 0.032 \\
\hline Industry $=$ Other Manufacturing & 1.323 & 0.001 & 1.356 & 0.000 \\
\hline Industry = Foods & 1.375 & 0.012 & 1.599 & 0.003 \\
\hline Industry $=$ Textiles & 1.309 & 0.037 & 1.293 & 0.065 \\
\hline Industry = Plastics \& rubber & 1.889 & 0.019 & 2.053 & 0.012 \\
\hline Industry $=$ Construction Section $\mathrm{F}$ & 1.895 & 0.000 & 2.025 & 0.000 \\
\hline Industry $=$ Services of Motor Vehicles & 2.144 & 0.000 & 2.521 & 0.000 \\
\hline Industry $=$ Wholesale & 1.585 & 0.000 & 1.646 & 0.000 \\
\hline Industry = Retail & 1.039 & 0.042 & 1.205 & 0.010 \\
\hline Industry $=$ Hotel and restaurants: section $\mathrm{H}$ & 1.966 & 0.000 & 2.052 & 0.000 \\
\hline Industry $=$ Transport Section I & 1.864 & 0.000 & 2.047 & 0.000 \\
\hline Legal Status = Privately held, limited liability compan & 0.794 & 0.021 & 0.940 & 0.000 \\
\hline Principal Owner Gender= Female $/$ Are any of the pri & 0.437 & 0.076 & 0.412 & 0.062 \\
\hline /cut_1_1 & 0.133 & 0.671 & 0.142 & 0.620 \\
\hline /cut_1_2 & 0.952 & 0.003 & 0.910 & 0.002 \\
\hline /cut 13 & 2.304 & 0.000 & 2.207 & 0.000 \\
\hline /cut_1_4 & 3.353 & 0.000 & 3.210 & 0.000 \\
\hline Athrho & & & 0.454 & 0.007 \\
\hline Underidentification test & \multicolumn{3}{|c|}{$\begin{array}{l}\text { (Kleibergen Paap rk LM statistic): } \\
\text { Chi sq(6) P val = }\end{array}$} & $\begin{array}{c}19.774 \\
0.003\end{array}$ \\
\hline Overidentification test & \multicolumn{3}{|c|}{$\begin{array}{l}\text { Hansen J statistic: } \\
\text { Chi sq(5) } \mathrm{P} \text { val }=\end{array}$} & $\begin{array}{l}6.840 \\
0.233\end{array}$ \\
\hline
\end{tabular}

Underidentification Test and Overidentification Test calculated on a IV linear model.

\begin{tabular}{|c|c|c|c|c|}
\hline \multirow{3}{*}{ REGRESSORS } & \multicolumn{4}{|c|}{ Political Instability } \\
\hline & \multicolumn{2}{|c|}{ OProbit } & \multicolumn{2}{|c|}{ IV OProbit } \\
\hline & Coef. & P value & Coef. & P value \\
\hline \multicolumn{5}{|l|}{ Size $=$ Small $>=5$ and $<=19$} \\
\hline Size $=$ Medium $>=20$ and $<=99$ & 0.064 & 0.839 & 0.398 & 0.323 \\
\hline Size $=$ Large $>=100$ & 0.664 & 0.055 & 0.342 & 0.635 \\
\hline Industry $=$ Textiles & 1.377 & 0.055 & 1.321 & 0.098 \\
\hline Industry $=$ Chemicals & 1.266 & 0.000 & 1.407 & 0.000 \\
\hline Industry $=$ Hotel and restaurants: section $\mathrm{H}$ & 0.455 & 0.095 & 0.475 & 0.080 \\
\hline Legal Status $=$ Sole (propietorship) & 0.710 & 0.061 & 0.833 & 0.022 \\
\hline Percentage held by largest owner ( $024 \%)$ & 1.383 & 0.000 & 0.793 & 0.076 \\
\hline Percentage held by largest owner (75 100\%) & 0.904 & 0.005 & 0.773 & 0.024 \\
\hline Principal Owner Gender= Female / Are any of the pri & 0.510 & 0.039 & 0.500 & 0.049 \\
\hline Internationally recognized quality certification $=$ Yes & 0.433 & 0.125 & 0.542 & 0.079 \\
\hline /cut 11 & 1.960 & 0.000 & 2.143 & 0.000 \\
\hline /cut_1_2 & 1.170 & 0.001 & 1.378 & 0.000 \\
\hline /cut_1_3 & 0.461 & 0.142 & 0.690 & 0.037 \\
\hline /cut_1_4 & 0.675 & 0.017 & 0.392 & 0.239 \\
\hline Athrho & & & 0.394 & 0.098 \\
\hline Underidentification test & \multicolumn{3}{|c|}{$\begin{array}{l}\text { (Kleibergen Paap rk LM statistic): } \\
\text { Chi sq(4) P val = }\end{array}$} & $\begin{array}{l}19.708 \\
0.001\end{array}$ \\
\hline Overidentification test & \multicolumn{3}{|c|}{$\begin{array}{l}\text { Hansen J statistic: } \\
\text { Chi sq(3) P val = }\end{array}$} & $\begin{array}{l}1.662 \\
0.645\end{array}$ \\
\hline
\end{tabular}

Underidentification Test and Overidentification Test calculated on a IV linear model. 
Model Selection (continued)

\begin{tabular}{|c|c|c|c|c|}
\hline \multirow{3}{*}{ REGRESSORS } & \multicolumn{4}{|c|}{ Corruption } \\
\hline & \multicolumn{2}{|c|}{ OProbit } & \multicolumn{2}{|c|}{ IV OProbit } \\
\hline & Coef. & P value & Coef. & P value \\
\hline \multicolumn{5}{|l|}{ Size $=$ Small $>=5$ and $<=19$} \\
\hline Size $=$ Medium $>=20$ and $<=99$ & 0.103 & 0.720 & 0.102 & 0.816 \\
\hline Size $=$ Large $>=100$ & 0.145 & 0.627 & 0.601 & 0.384 \\
\hline City $=$ Santa Cruz & 0.751 & 0.001 & 0.662 & 0.022 \\
\hline Industry $=$ Textiles & 2.189 & 0.000 & 2.117 & 0.000 \\
\hline Industry $=$ Plastics \& rubber & 0.832 & 0.089 & 0.934 & 0.049 \\
\hline Industry $=$ Hotel and restaurants: section $\mathrm{H}$ & 0.935 & 0.007 & 0.930 & 0.006 \\
\hline Industry $=$ Transport Section I & 0.823 & 0.048 & 0.770 & 0.088 \\
\hline Percentage held by largest owner $(2549 \%)$ & 1.045 & 0.008 & 1.016 & 0.009 \\
\hline Percentage held by largest owner ( $5074 \%)$ & 0.721 & 0.019 & 0.687 & 0.026 \\
\hline Principal Owner Gender $=$ Female $/$ Are any of the pri & 0.791 & 0.000 & 0.795 & 0.000 \\
\hline Internationally $\quad$ recognized quality certification $=$ Yes & 1.511 & 0.000 & 1.473 & 0.000 \\
\hline Internationally recognized quality certification $=$ No & 1.215 & 0.001 & 1.282 & 0.000 \\
\hline /cut 11 & 0.109 & 0.735 & 0.235 & 0.488 \\
\hline /cut 12 & 0.689 & 0.063 & 0.807 & 0.029 \\
\hline /cut 13 & 1.164 & 0.002 & 1.279 & 0.001 \\
\hline /cut 14 & 2.474 & 0.000 & 2.580 & 0.000 \\
\hline Athrho & & & 0.207 & 0.405 \\
\hline Underidentification test & $\begin{array}{l}\text { (Kleibergen } \\
\text { Chi sq(4) P }\end{array}$ & rk LM statistic): & & $\begin{array}{c}4770.000 \\
0.000\end{array}$ \\
\hline Overidentification test & $\begin{array}{l}\text { Hansen J st: } \\
\text { Chi sq(3) P }\end{array}$ & & & $\begin{array}{c}12.609 \\
0.027\end{array}$ \\
\hline
\end{tabular}

Underidentification Test and Overidentification Test calculated on a IV linear model

\begin{tabular}{|c|c|c|c|c|}
\hline \multirow{3}{*}{ REGRESSORS } & \multicolumn{4}{|c|}{ Access to Financing } \\
\hline & \multicolumn{2}{|c|}{ OProbit } & \multicolumn{2}{|c|}{ IV OProbit } \\
\hline & Coef. & P value & Coef. & P value \\
\hline \multicolumn{5}{|l|}{ Size $=$ Small $>=5$ and $<=19$} \\
\hline Size $=$ Medium $>=20$ and $<=99$ & 0.596 & 0.025 & 1.413 & 0.000 \\
\hline Size $=$ Large $>=100$ & 1.069 & 0.000 & 2.965 & 0.000 \\
\hline Type $=$ Manufacturing & 0.592 & 0.036 & 0.492 & 0.062 \\
\hline City $=$ Santa Cruz & 0.120 & 0.582 & 0.324 & 0.087 \\
\hline Industry $=$ Foods & 0.501 & 0.083 & 0.900 & 0.001 \\
\hline Industry $=$ Textiles & 2.349 & 0.000 & 1.970 & 0.012 \\
\hline Legal Status = Publicly listed company & 1.225 & 0.000 & 1.209 & 0.026 \\
\hline Legal Status $=$ Sole (propietorship) & 0.015 & 0.972 & 0.743 & 0.026 \\
\hline Legal Status $=$ Partnership & 0.243 & 0.227 & 0.687 & 0.002 \\
\hline Percentage held by largest owner $(024 \%)$ & 0.766 & 0.065 & 1.775 & 0.001 \\
\hline Percentage held by largest owner (5074\%) & 0.732 & 0.001 & 0.497 & 0.020 \\
\hline Internationally recognized quality certification $=$ Yes & 1.105 & 0.000 & 1.033 & 0.000 \\
\hline /cut 11 & 0.591 & 0.064 & 1.379 & 0.000 \\
\hline /cut 12 & 0.242 & 0.450 & 1.093 & 0.000 \\
\hline /cut 13 & 0.961 & 0.002 & 0.105 & 0.771 \\
\hline /cut 14 & 2.199 & 0.000 & 0.964 & 0.106 \\
\hline Athrho & & & 1.120 & 0.001 \\
\hline Underidentification test & $\begin{array}{l}\text { (Kleibergen } \\
\text { Chi sq(6) P }\end{array}$ & rk LM stat & & $\begin{array}{c}2912.000 \\
0.000\end{array}$ \\
\hline Overidentification test & $\begin{array}{l}\text { Hansen J st } \\
\text { Chi sq(5) P }\end{array}$ & & & $\begin{array}{l}4.293 \\
0.508\end{array}$ \\
\hline
\end{tabular}

Underidentification Test and Overidentification Test calculated on a IV linear model. 
Model Selection (continued)

\begin{tabular}{|c|c|c|c|c|}
\hline \multirow{3}{*}{ REGRESSORS } & \multicolumn{4}{|c|}{ Labor Regulations } \\
\hline & \multicolumn{2}{|c|}{ OProbit } & \multicolumn{2}{|c|}{ IV OProbit } \\
\hline & Coef. & Pvalue & Coef. & Pvalue \\
\hline \multicolumn{5}{|l|}{ Size $=$ Small $>=5$ and $<=19$} \\
\hline Size $=$ Medium $>=20$ and $<=99$ & 0.016 & 0.953 & 0.170 & 0.594 \\
\hline Size $=$ Large $>=100$ & 0.484 & 0.052 & 0.826 & 0.034 \\
\hline Type $=$ Manufacturing & 1.131 & 0.000 & 1.128 & 0.000 \\
\hline City $=\mathrm{LaPaz}$ & 0.938 & 0.017 & 0.960 & 0.017 \\
\hline City $=$ Santa Cruz & 0.835 & 0.021 & 0.905 & 0.015 \\
\hline Industry $=$ Other Manufacturing & 0.942 & 0.000 & 0.900 & 0.001 \\
\hline Industry $=$ Foods & 0.946 & 0.001 & 0.866 & 0.010 \\
\hline Industry $=$ Garments & 1.884 & 0.020 & 1.804 & 0.025 \\
\hline Industry = Plastics \& rubber & 1.430 & 0.016 & 1.341 & 0.029 \\
\hline Industry $=$ Transport Section I & 1.024 & 0.023 & 1.073 & 0.019 \\
\hline Legal Status = Publicly listed company & 0.682 & 0.047 & 0.735 & 0.034 \\
\hline Legal Status = Partnership & 0.477 & 0.055 & 0.482 & 0.055 \\
\hline Percentage held by largest owner ( $5074 \%$ ) & 0.587 & 0.014 & 0.575 & 0.017 \\
\hline Percentage held by largest owner ( $75100 \%)$ & 0.544 & 0.062 & 0.574 & 0.053 \\
\hline Principal Owner Gender= Female / Are any of the pri & 0.608 & 0.006 & 0.614 & 0.006 \\
\hline /aut_1_1 & 2.591 & 0.000 & 2.545 & 0.000 \\
\hline /out_1_2 & 1.497 & 0.000 & 1.468 & 0.000 \\
\hline /out 13 & 0.220 & 0.560 & 0.196 & 0.603 \\
\hline /aut_1_4 & 0.901 & 0.031 & 0.933 & 0.025 \\
\hline Athrho & & & 0.161 & 0.300 \\
\hline Underidentification test & $\begin{array}{l}\text { (Kleibergen } \\
\text { Chi sq(7) P }\end{array}$ & tk LM stat & & $\begin{array}{c}4626.000 \\
0.000 \\
\end{array}$ \\
\hline Overidentification test & $\begin{array}{l}\text { Hansen J st } \\
\text { Chi sq(6) P }\end{array}$ & & & $\begin{array}{l}3.973 \\
0.680\end{array}$ \\
\hline
\end{tabular}

Underidentification Test and Overidentification Test calculated on a IV linear model.

\begin{tabular}{|c|c|c|c|c|}
\hline \multirow{3}{*}{ REGRESSORS } & \multicolumn{4}{|c|}{ Inadequately Educated Workforce } \\
\hline & \multicolumn{2}{|c|}{ OProbit } & \multicolumn{2}{|c|}{ IV OProbit } \\
\hline & Coef. & $P$ value & Coef. & P value \\
\hline \multicolumn{5}{|l|}{ Size $=$ Small $>=5$ and $<=19$} \\
\hline Size $=$ Medium $>=20$ and $<=99$ & 0.293 & 0.291 & 0.504 & 0.180 \\
\hline Size $=$ Large $>=100$ & 0.106 & 0.667 & 0.550 & 0.340 \\
\hline Type $=$ Retail & 0.595 & 0.081 & 0.611 & 0.076 \\
\hline City $=$ Santa Cruz & 0.389 & 0.095 & 0.447 & 0.041 \\
\hline Industry $=$ Other Manufacturing & 0.829 & 0.013 & 0.822 & 0.013 \\
\hline Industry $=$ Textiles & 2.050 & 0.025 & 2.098 & 0.031 \\
\hline Industry $=$ Garments & 0.735 & 0.076 & 0.655 & 0.105 \\
\hline Industry $=$ Plastics $\&$ rubber & 1.467 & 0.033 & 1.571 & 0.019 \\
\hline Industry $=$ Construction Section F & 0.938 & 0.043 & 0.946 & 0.025 \\
\hline Industry $=$ Retail & 0.933 & 0.097 & 0.938 & 0.080 \\
\hline Percentage held by largest owner $(024 \%)$ & 1.733 & 0.000 & 1.505 & 0.011 \\
\hline Percentage held by largest owner $(5074 \%)$ & 0.514 & 0.043 & 0.532 & 0.030 \\
\hline Internationally recognized quality certification $=$ Yes & 0.707 & 0.018 & 0.692 & 0.028 \\
\hline Internationally recognized quality certification $=$ No & 0.776 & 0.010 & 0.694 & 0.023 \\
\hline /cut_1_1 & 0.781 & 0.005 & 0.922 & 0.005 \\
\hline /cut 12 & 0.278 & 0.460 & 0.130 & 0.769 \\
\hline /cut_1_3 & 1.427 & 0.000 & 1.267 & 0.011 \\
\hline /cut_1_4 & 2.399 & 0.000 & 2.231 & 0.000 \\
\hline Athrho & & & 0.187 & 0.424 \\
\hline Underidentification test & \multicolumn{3}{|c|}{$\begin{array}{l}\text { (Kleibergen Paap rk LM statistic): } \\
\text { Chi sq(6) P val = }\end{array}$} & $\begin{array}{c}4536.000 \\
0.000\end{array}$ \\
\hline Overidentification test & \multicolumn{3}{|c|}{$\begin{array}{l}\text { Hansen J statistic: } \\
\text { Chi sq(5) P val = }\end{array}$} & $\begin{array}{l}2.457 \\
0.652\end{array}$ \\
\hline
\end{tabular}

Underidentification Test and Overidentification Test calculated on a IV linear model. 


\section{APPENDIX III}

Conditional Likelihood Minus Unconditional Likelihood
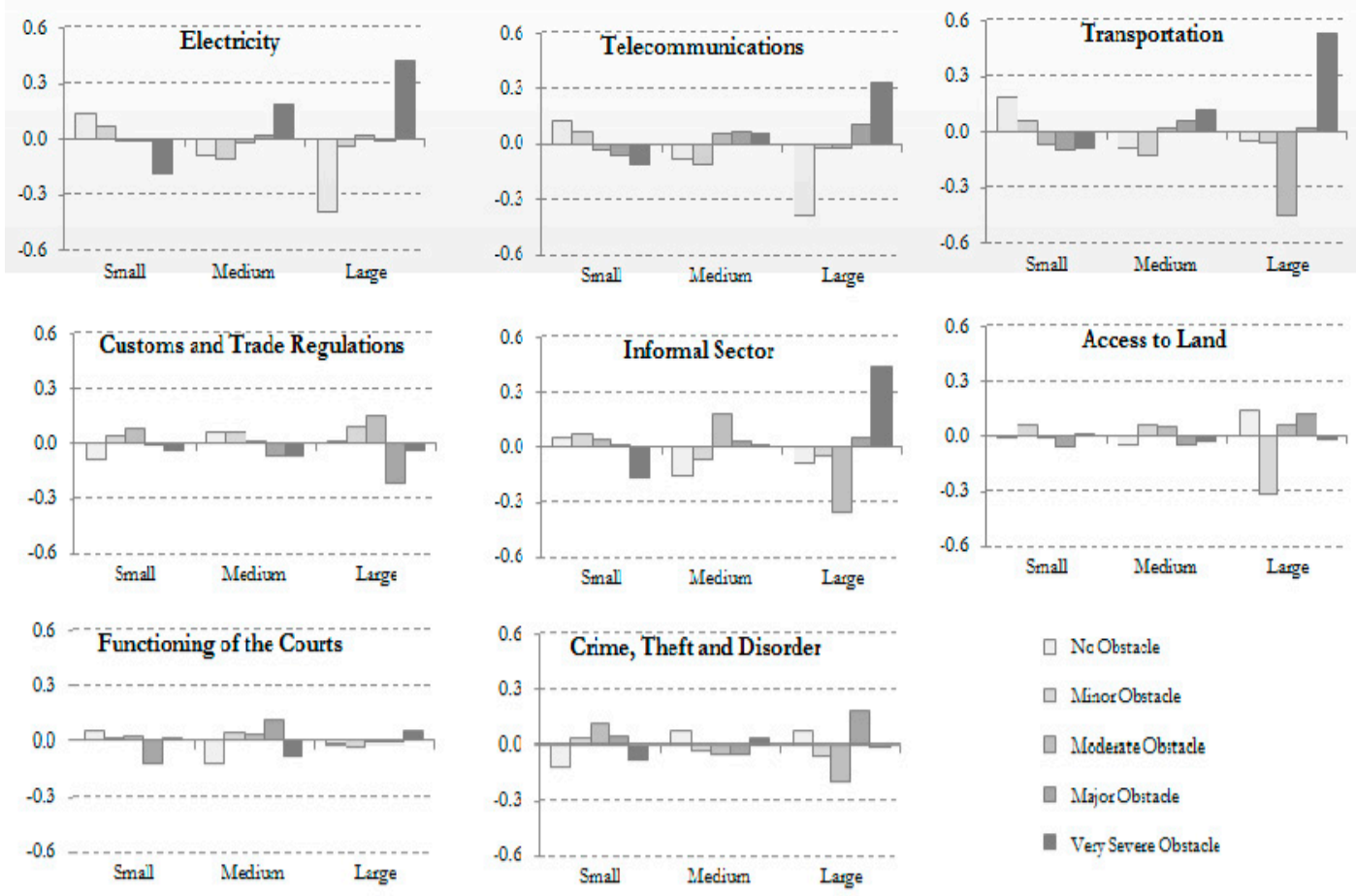
$\square$ No Obstasle
$\square$ MinorObstacle
- Moderate Obitacle
- Major Obitade
Very Sereere Obstacle
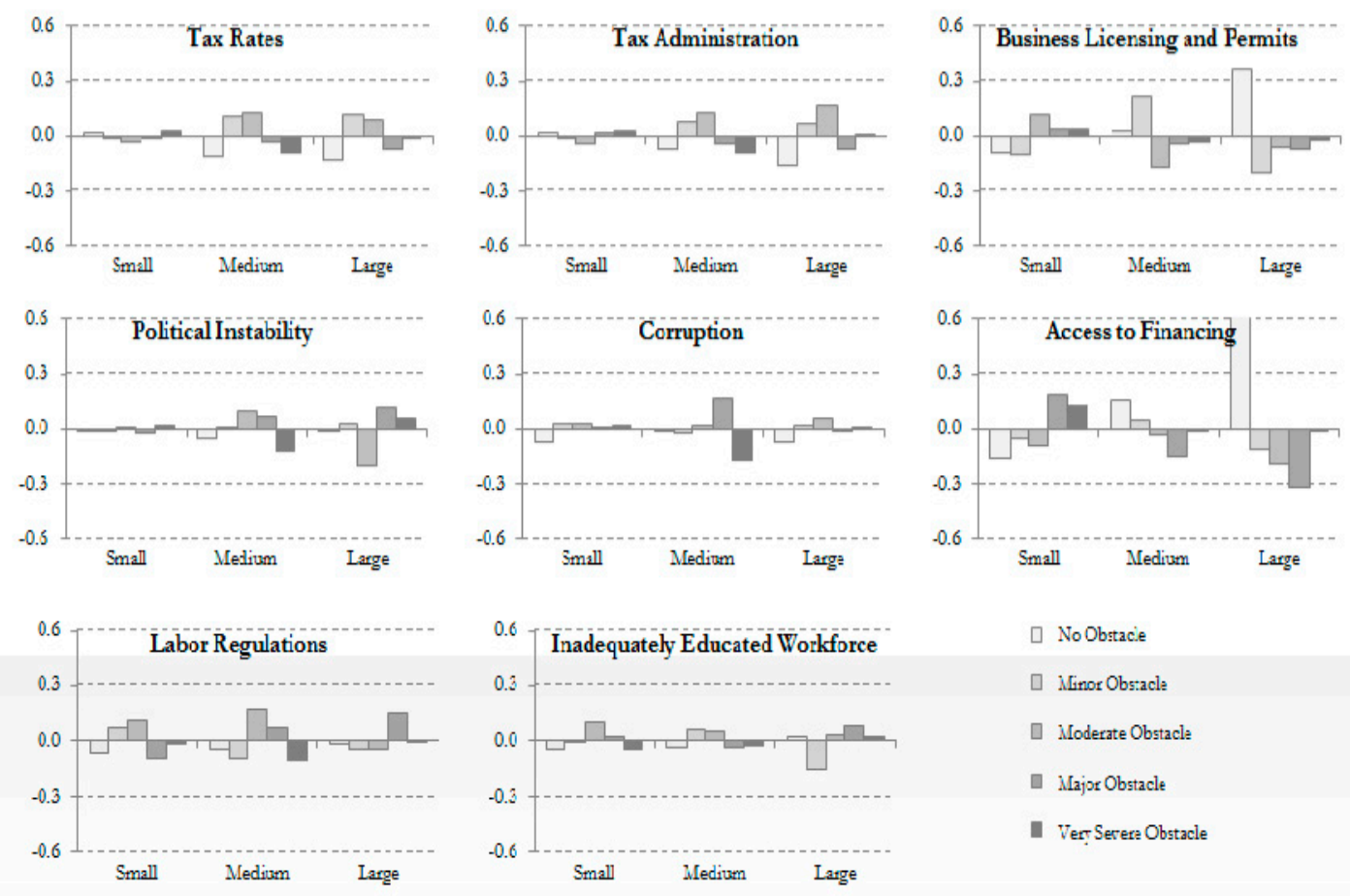
$\square$ No Obstacie
(4) Minor Obs:acle
\ Moderate Obstacls
- Major Obstacle
- VerTSerer: Obstacle 